\title{
Information Rigidity and the Expectations Formation Process: A Simple Framework and New Facts ${ }^{*}$
}

\author{
Olivier Coibion \\ College of William and Mary \\ Yuriy Gorodnichenko \\ University of California, Berkeley and NBER \\ College of William and Mary \\ Department of Economics \\ Working Paper Number 102
}

November 2010

\footnotetext{
${ }^{*}$ We are grateful to Bob Archibald, Christopher Crowe, Zeno Enders, Ulrich Fritsche, Pierre-Olivier Gourinchas, Ed Knotek, Javier Reyes, David Romer and Chris Sims for helpful comments as well as seminar participants at the Bank of France, CESifo/LMU Conference on Macroeconomics and Survey Data, College of William and Mary, Duke, George Washington University, IMF, Minnesota Fed, Richmond Fed and University of Arkansas.
} 
COLLEGE OF WILLIAM AND MARY

DEPARTMENT OF ECONOMICS

WORKING PAPER \# 102

November 2010

\title{
Information Rigidity and the Expectations Formation Process: A Simple Framework and New Facts
}

\begin{abstract}
We propose a new approach to test of the null of full-information rational expectations which is informative about whether rejections of the null reflect departures from rationality or fullinformation. This approach can also quantify the economic significance of departures from the null by mapping them into the underlying degree of information rigidity faced by economic agents. Applying this approach to both U.S. and cross-country data of professional forecasters and other economic agents yields pervasive evidence of informational rigidities that can be explained by models of imperfect information. Furthermore, the proposed approach sheds new light on the implications of policies such as inflation-targeting and those leading to the Great Moderation on expectations. Finally, we document evidence of state-dependence in the expectations formation process.
\end{abstract}

JEL Codes: E3, E4, E5.

Keywords: Expectations, Information Rigidity, Survey Forecasts.

Olivier Coibion

Department of Economics

College of William and Mary

Williamsburg, VA 23187-8795

ocoibion@wm.edu
Yuriy Gorodnichenko

Department of Economics

University of California, Berkeley

Berkeley, CA 94720-3880

ygorodni@econ.berkeley.edu 


\section{Introduction}

Expectations matter. How much to consume or save, what price to set, and whether to hire or fire workers are just some of the fundamental decisions underlying macroeconomic dynamics that hinge upon agents' expectations of the future. Yet how those expectations are formed, and how best to model this process, remains an open question. From the simple automatons of adaptive expectations to the allknowing agents of modern full-information rational expectations models, macroeconomists have considered a wide variety of frameworks to model the expectations formation process, yielding radically different results for macroeconomic dynamics and policy implications. Recent work on rational expectations models with informational frictions such as Mankiw and Reis (2002), Woodford (2001), and Sims (2003) has emphasized how informational rigidities can account for otherwise puzzling empirical findings but these same frictions can also lead to policy prescriptions that differ from those under models with full-information. ${ }^{1}$ Despite a growing body of work studying the implications of possible departures from full-information rational expectations, the empirical evidence against this assumption underlying most modern macroeconomic models has been limited. In particular, while statistical evidence against the null is commonly uncovered, the economic significance of these rejections remains unclear.

Building from the predictions of rational expectations models with informational rigidities, we propose a novel approach to test the null of full-information rational expectations in a way that sheds new light on possible departures from the null. Our baseline specification relates ex post mean forecast errors to the ex ante revision of the average forecast across agents. While this specification is just a special case of the traditional test of full-information rational expectations (FIRE) in which one assesses whether previously available information can predict ex post mean forecast errors, our specification possesses multiple advantages over this traditional approach. ${ }^{2}$ First, we rely on the predictions of theoretical models of informational rigidities to guide our choice of the relevant regressors. This mitigates the data-mining concern associated with the traditional approach in which, after trying enough potential regressors, one is bound to reject the null of FIRE. Second, models of informational rigidities make specific predictions about the sign of the coefficient on forecast revisions, so that our specification provides guidance not only about the null of FIRE but also about alternative models. As a result, our framework can help determine

\footnotetext{
${ }^{1}$ For example, Ball et al. (2005) show that price-level targeting is optimal in sticky-information models whereas inflation targeting is optimal in a sticky-price model. Paciello and Wiederholt (2010) document how rational inattention as in Sims (2003) alters optimal monetary policy. Likewise, Mankiw and Reis (2002) argue that the observed delayed response of inflation to monetary policy shocks is not readily matched by New Keynesian models without the addition of informational rigidities or the counterfactual assumption of price indexation. Roberts (1997, 1998) and Adam and Padula (2003) demonstrate that empirical estimates of the slope of the New Keynesian Phillips Curve have the correct sign when conditioning on survey measures of inflation expectations while this is typically not the case under the assumption of full-information rational expectations. Piazzesi and Schneider (2008), Gourinchas and Tornell (2004) and Bachetta et al. (2008) all identify links between systematic forecast errors in survey forecasts and puzzles in various financial markets.

${ }^{2}$ See Pesaran and Weale (2006) for a survey of this literature.
} 
whether rejections of the null should be interpreted as rejecting either the rationality of expectations or the full-information assumption. Third, we show that the coefficient on forecast revisions maps one-to-one into the underlying degree of information rigidity. Our approach can therefore not only test the null of FIRE against well-specified alternatives but also provide a metric by which to assess the economic significance of departures from the null of FIRE.

Two theoretical rational expectations models of informational frictions motivate our empirical specification. In the sticky-information model of Mankiw and Reis (2002), agents update their information sets infrequently as a result of fixed costs to the acquisition of information. When they do update their information sets, they acquire full-information rational expectations. The degree of information rigidity in this model is then the probability of not acquiring new information each period. The second class of models we consider consists of imperfect information models such as Woodford (2001), Sims (2003), and Mackowiak and Wiederholt (2009). Here, agents continuously update their information sets but, because they can never fully observe the true state, they form and update beliefs about the underlying fundamentals via a signal extraction problem. ${ }^{3}$ Strikingly, both models predict the same relationship between ex post mean forecast errors and the ex ante mean forecast revision such that the coefficient on forecast revisions depends only on the degree of information rigidity in each model.

The resulting empirical specification can be applied to study informational rigidities for a variety of economic agents such as consumers, firms, central banks and financial market participants for whom forecast data are available. As a first step, we focus on inflation forecasts from the U.S. Survey of Professional Forecasters (SPF) for two reasons. First, inflation forecasts have received the most attention in the literature so that these results are more readily comparable to previous work. Second, because professional forecasters are some of the most informed economic agents, uncovering significant informational rigidities for these agents likely presents a lower bound on the importance of informational rigidities for other less-informed economic agents. From 1969-2010, we can strongly reject the null of FIRE and find that the estimated coefficient on forecast revisions is positive, consistent with the prediction of rational expectations models incorporating informational rigidities. Additional coefficient restrictions implied by these models cannot be rejected and past information incorporated in other economic variables loses much of its predictive power for ex post mean forecast errors once the forecast revision is controlled for. Furthermore, the implied degree of information rigidity is high: in the context of sticky-information models, it implies an average duration of six to seven months between information updates, while in imperfect information models it implies that new information receives less than half of the weight that it would under full information when agents are updating their forecasts. We document

${ }^{3}$ Earlier work in this tradition includes Lucas (1972) and Kydland and Prescott (1982). A related approach emphasizes differences in agents' priors about parameter values rather than differences in information sets. See for example Patton and Timmermann (2010). 
that qualitatively similar results obtain for different subsets of professional forecasters, such as academics, commercial banks, and non-financial businesses, as well as for consumers and financial market-based inflation expectations. Thus, our results are unlikely to be driven by either strategic behavior on the part of professional forecasters or reputational considerations.

In addition, we apply our specification to a much broader set of forecasted macroeconomic variables. First, the SPF includes historical forecasts for four other macroeconomic variables going back to 1968, including real GDP and unemployment, at multiple forecasting horizons. Our approach can exploit both the multiple forecasting horizons and different macroeconomic variables, allowing us to extract more precise estimates of informational rigidities than in previous work. Pooling across these variables and forecasting horizons leads to even stronger rejections of the null of FIRE, again in the direction predicted by models of informational rigidities. Second, starting in 1981, the SPF includes forecasts of seven additional macroeconomic variables, again at multiple forecasting horizons. Using this larger set of variables confirms the baseline finding: we can reject the null of FIRE in exactly the direction predicted by models with informational frictions and the estimates point to economically significant degrees of informational rigidities. Third, we utilize an additional survey of professional forecasters constructed by Consensus Economics which includes quarterly historical forecasts since 1989 of five macroeconomic variables for the G-7 and five additional industrialized countries, again at multiple forecasting horizons. Pooling across these countries, variables and horizons, yields an almost identical coefficient on forecast revisions, providing further evidence that professional forecasters are subject to significant informational rigidities.

Our approach can also shed light on the relative merit of different models of informational rigidities. For example, the sticky-information model implies a common rate of information updating for all macroeconomic variables, whereas imperfect information models imply that the degree of information rigidity associated with a macroeconomic variable should vary according to the persistence of each variable and the signal-noise ratio associated with it. Across datasets, we find robust evidence that the degree of information rigidity varies systematically across macroeconomic variables and that this crosssectional variation is consistent with the predicted determinants of imperfect information models: the persistence of a variable and measures of the signal-noise ratio can account for about 20-30 percent of the variation in the estimated degree of information rigidity across countries and macroeconomic variables in the Consensus Economics dataset. Thus, imperfect information models appear to be a reasonable description of the underlying expectations formation process for professional forecasters.

Because our empirical specification allows us to recover estimates of the underlying degree of information rigidity, we also consider some policy determinants of the expectations formation process. For example, the monetary policy changes enacted by Volcker contributed to the Great Moderation 
(Clarida et al. (2000), Coibion and Gorodnichenko (2009)), the period of diminished macroeconomic volatility since the early to mid-1980s. According to models with informational rigidities, such a decline in volatility should result in a higher degree of inattention. We study the low-frequency time variation in the estimated degree of information rigidity among U.S. professional forecasters and find evidence that accords remarkably well with this intuition: the degree of information rigidity fell consistently throughout the 1970s and early 1980s when macroeconomic volatility was high, reaching a minimum around 198384. Since then, the degree of information rigidity has been consistently rising as macroeconomic volatility has been subdued. One interpretation of this result could be that the changes in monetary policy enacted by Volcker helped stabilize the economy in the Great Moderation, but this economic stabilization also promoted greater inattention on the part of economic agents, thereby, in the end, making the economy more susceptible to economic shocks. This suggests an additional mechanism, along with increased risk-taking on the part of financial market participants, through which the Great Moderation may have contributed to the severity of the Great Recession.

Our approach is also well-suited to evaluate and quantify the effect of policy or institutional changes on the expectations formation process. To illustrate, we first study the effect of central bank independence on the expectations formation process and we find a strong positive relationship between central bank independence and information rigidity. We also consider the adoption of inflation-targeting by central banks within our cross-country data, a policy explicitly expected to stabilize or "anchor" agents' inflation expectations. Such regimes should, if credible, increase inattention to inflation on the part of economic agents leading to lower volatility in expectations of future outcomes. We find that the effect of adopting an inflation-targeting regime on the degree of inattention in inflationary expectations of professional forecasters is small and not statistically significant, casting doubt on the efficacy of this policy, at least among the already-stable set of countries in our sample. This approach could readily be extended to a larger set of countries and other policy issues such as exchange rate regimes which are predicted to have important effects on expectations. Thus, an additional contribution of the paper is to provide a framework for analyzing the effects of different policy regimes on the expectations formation process of economic agents.

While research on sticky information and imperfect information typically expresses these notions in a time-dependent setting, one might naturally expect large and visible shocks to affect the rate of information-acquisition and processing by economic agents, i.e. state-dependence should be characteristic in the face of large shocks as theoretically documented in Gorodnichenko (2008). We consider this possibility by studying the time-variation in the degree of informational rigidities in two cases. First, we estimate the average effect of recessions on the degree of information rigidity in the U.S. since 1969. We find that the degree of information rigidity declines substantially after a few quarters of being in a 
recession and gradually recovers over time. Second, we consider the natural experiment provided by the attack of September $11^{\text {th }}$, 2001, which was an immediately recognizable and economically potent shock leading to large forecast revisions by professional forecasters thereafter. Because of the visibility of this shock, one might expect that these forecast revisions would not have been subject to the same degree of informational rigidities as normal business cycle conditions. Consistent with this prior, we find that professional forecasts in the U.S. and other countries were not subject to important informational rigidities shortly after the $9 / 11$ shock. In short, we document clear evidence of state-dependence in the expectations formation process in the presence of large economic shocks, a feature of the data which is not commonly incorporated into models of information rigidities.

This paper is closely related to recent empirical work trying to ascertain the nature of the expectations formation process. For example, Mankiw et al. (2004) assess whether a sticky-information model can replicate some stylized facts about the predictability of forecast errors by professional forecasters while Andolfatto et al. (2007) consider whether imperfect information with respect to the inflation target of the central bank can account for observed deviations from FIRE. Khan and Zhu (2006), Kiley (2007), and Coibion (2010) assess the validity of sticky information using estimates of its predicted Phillips curve. One advantage of our approach is that we can directly recover an estimate of the degree of information rigidity without having to make auxiliary assumptions about the model, such as the nature of price-setting decisions. Furthermore, our approach allows us to differentiate between sticky-information and imperfect information models. Coibion and Gorodnichenko (2008) study the evidence for stickyinformation and imperfect information models but do so by estimating the response of forecast errors and disagreement to structural shocks whereas our approach does not require the identification of any shock. In the same spirit, Branch (2007) compares the fit of sticky-information and model-switching characterizations of the expectations formation process while Carroll (2003) tests an epidemiological model of expectations in which information diffuses over time from professional forecasters to consumers. However, these papers focus almost exclusively on inflationary expectations whereas we utilize forecasts for a wide variety of macroeconomic variables as well as cross-country data. Furthermore, we study the deeper determinants of information rigidity such as the effects of macroeconomic volatility and institutions.

The paper is structured as follows. Section 2 presents the predicted relationship between ex post mean forecast errors and ex ante mean forecast revisions in sticky-information and imperfect information models. Section 3 describes the empirical strategy and provides results for inflation forecasts of professional forecasters and other agents, as well as broader evidence from forecasts of other macroeconomic variables. Section 4 presents evidence on the underlying macroeconomic and policy 
determinants of informational rigidities and documents a likely role for state-dependence in the expectations formation process. Section 5 concludes.

\section{Forecast Errors, Forecast Revisions and Informational Rigidities}

In this section, we present two models of informational rigidities and derive their respective predictions for the relationship between ex post mean forecast errors and ex ante mean forecast revisions.

\subsection{Sticky Information}

Mankiw and Reis (2002) proposed a model of inattentive agents who update their information sets each period with probability $(1-\lambda)$ but acquire no new information with probability $\lambda$, so that $\lambda$ can be interpreted as the degree of information rigidity and $1 /(1-\lambda)$ is the average duration between information updates. When agents update their information sets, they acquire full information and have rational expectations. Reis (2006) shows how this time-dependent updating of information sets obtains when firms face a fixed cost to updating their information. The average time $t$ forecast across agents $\left(F_{t}\right)$ of a variable $x$ at time $t+h$ is a weighted average of current and past full-information rational expectations forecasts $\left(E_{t-j}\right)$ of the variable such that

$$
F_{t} x_{t+h}=(1-\lambda) \sum_{j=0}^{\infty} \lambda^{j} E_{t-j} x_{t+h} .
$$

The average forecast at time $t-1$ can similarly be written as

$$
F_{t-1} x_{t+h}=(1-\lambda) \sum_{j=0}^{\infty} \lambda^{j} E_{t-1-j} x_{t+h}
$$

which implies that the current average forecast is just a weighted average of the previous period's forecast and the current rational expectation of variable $x$ at time $t+h$

$$
F_{t} x_{t+h}=(1-\lambda) E_{t} x_{t+h}+\lambda F_{t-1} x_{t+h} .
$$

Full-information rational expectations are such that

$$
E_{t} x_{t+h}=x_{t+h}+v_{t+h, t}
$$

where $v_{t+h, t}$ is the rational expectations error and is thus uncorrelated with information dated $t$ or earlier.

Combining (3) and (4) yields the predicted relationship between the ex post mean forecast error across agents and the forecast revision

$$
x_{t+h}-F_{t} x_{t+h}=\frac{\lambda}{1-\lambda} \Delta F_{t} x_{t+h}+v_{t+h, t}
$$

where $\Delta F_{t} x_{t+h}=F_{t} x_{t+h}-F_{t-1} x_{t+h}$. Importantly, the coefficient on the forecast revision depends only the degree of information rigidity $\lambda$. In the special case of no informational frictions, $\lambda=0$ and the specification collapses to equation (4), i.e. the average forecast error is unpredictable using information dated $t$ or earlier. Because the sticky-information model implies a single rate of information acquisition, 
equation (5) holds for any macroeconomic variable and any forecasting horizon. ${ }^{4}$ In addition, this specification will hold regardless of the structure of the rest of the model.

\subsection{Imperfect Information}

We also consider models in which agents know the structure of the model and underlying parameter values, continuously update their information sets, but never fully observe the state. This class of models includes most famously the Lucas (1972) islands model but also a wide variety of limited information settings considered in the literature. For example, Kydland and Prescott (1982) assume that the level of technology reflects both permanent and transitory shocks but that agents cannot separately identify these two components. More recently, Woodford (2001) considers an environment in which firms observe aggregate demand subject to idiosyncratic errors, which combined with strategic complementarity in price-setting, can account for the persistent effect of monetary policy shocks. Suppose that a macroeconomic variable follows an $\mathrm{AR}(1)$ process

$$
x_{t}=\rho x_{t-1}+v_{t}
$$

where $0 \leq \rho \leq 1$. Agents cannot directly observe $x$ but instead receive a signal $x_{t}^{i}$ such that

$$
x_{t}^{i}=x_{t}+\omega_{t}^{i}
$$

where $\omega_{t}^{i}$ represents noise which may be correlated across agents. Each agent $i$ then generates optimal forecasts $F_{t}^{i} x_{t+h}$ given their information sets via the Kalman filter

$$
\begin{aligned}
& F_{t}^{i} x_{t}=G x_{t}^{i}+(1-G) F_{t-1}^{i} x_{t} \\
& F_{t}^{i} x_{t+h}=\rho^{h} F_{t}^{i} x_{t},
\end{aligned}
$$

where $G$ is the Kalman gain which represents the relative weight placed on new information relative to previous forecasts. When the signal is perfectly revealing about the true state, $G=1$; while the presence of noise induces $G<1$. Thus, $(1-G)$ can be interpreted as the degree of information rigidity in this model. ${ }^{5}$

\footnotetext{
${ }^{4}$ Carroll (2003) proposes an epidemiological model of information diffusion in which consumers acquire rational expectations forecasts in a time dependent setting from occasional activities such as reading the newspaper. It is conceivable in Carroll's model for sticky information agents to have different rates of information updating for different macroeconomic variables since the full-information rational expectations are formulated by other agents. However, because we focus primarily on professional forecasters who do not have access to superior forecasts from other agents, we assume that these forecasters formulate the full-information rational expectations updates themselves. Because the latter requires solving for all variables simultaneously, the rate of information updating must be common across variables. The same logic applies for different forecasting horizons.

${ }^{5}$ In general, the persistence of macroeconomic variables is also a function of the degree of information rigidity. We focus on the equilibrium outcome where the effect of information rigidity is fully incorporated in the persistence of the series. Since the persistence of macroeconomic variables is increasing in information rigidities and the degree of information rigidity is decreasing in the persistence, there will be unique equilibrium levels of persistence and information rigidity in the model.
} 
Averaging across agents and rearranging, one can show that the following relationship between ex post mean forecast errors and ex ante mean forecast revisions holds when the average of the noise across agents is zero

$$
x_{t+h}-F_{t} x_{t+h}=\frac{1-G}{G} \Delta F_{t} x_{t+h}+\varepsilon_{t+h, t}
$$

where $\varepsilon_{t+h, t}=\sum_{i=1}^{h} \rho^{i} v_{t+i}$ is the rational expectations error and $F$ denotes the average forecast across agents. ${ }^{6}$ Thus, while individual forecasts are optimal conditional on each agent's information set, the ex post mean forecast error is systematically predictable using ex ante mean forecast revisions. This specification is identical to that obtained under sticky-information, when $(1-G)$ is interpreted as the degree of information rigidity. In contrast to equation (5) derived under sticky information, the coefficient on forecast revisions need not be the same for different macroeconomic variables or forecast horizons in imperfect information models. Instead, the coefficient will vary with the determinants of the Kalman gain, e.g. the persistence of the series and the signal-noise ratio.

\section{Tests of FIRE and New Evidence on Informational Rigidities}

This section a) describes our empirical strategy and relates it to previous literature; b) applies our approach to inflation forecasts of U.S. professional forecasters, consumers, and financial market participants; c) considers broader evidence of informational rigidities pooled across macroeconomic variables as well as d) cross-country evidence on informational rigidities.

\subsection{A New Approach for Assessing the Nature of the Expectations Formation Process}

The sticky information and imperfect information models both point to the same relationship between ex post mean forecast errors and ex ante mean forecast revisions such that the coefficient on forecast revisions maps one to one into the underlying degree of informational rigidities. This relationship can be readily estimated for a given macroeconomic variable $x$, mean forecasts across agents $F x$ and forecasting horizon $h$ using the following empirical specification:

$$
x_{t+h}-F_{t} x_{t+h}=c+\beta \Delta F_{t} x_{t+h}+\varepsilon_{t}
$$

This specification is just a special case of the more general test of FIRE commonly employed in the literature in which the forecast error is regressed on a subset of the information available to agents at the time the forecast was made, i.e.

$$
x_{t+h}-F_{t} x_{t+h}=c+\delta z_{t}+\varepsilon_{t} .
$$

Under the null of FIRE, forecast errors (the LHS) should be uncorrelated with all past information (any variable $z$ dated $t$ or earlier) and should have a constant of zero. Our empirical specification in contrast

\footnotetext{
${ }^{6}$ When the average noise is nonzero, this introduces another component to the error term, dated time $t$ and uncorrelated with information from $t-1$ and earlier. In this case, our baseline empirical specification cannot be estimated by OLS. We generated equivalent results as those in the paper using instrumental variables dated by $t-1$ and earlier and reached nearly identical conclusions. Hence, we focus on the simpler OLS case.
} 
imposes that the RHS variable be the revision in forecasts of the relevant time horizon. Despite the fact that our specification appears to just be a special case of the more general test, it addresses several important shortcomings of traditional tests.

The first limitation comes from the absence of any theoretical guidance in traditional applications of (11) as to which variables should be included on the RHS. This leads to important data-mining concerns: if a researcher tries enough macroeconomic variables and lags thereof, the null hypothesis of a zero coefficient is bound to be rejected. Consider a typical exercise applying (11) to inflation forecasts. Following much of the literature, we focus on mean inflation forecasts for the current and next three quarters from the Survey of Professional Forecasters from 1969 to 2010. Forecast errors are constructed using forecasts made at the relevant date and real-time data available one year after the relevant date. A common first step in the literature is to include the contemporaneous forecast of future inflation on the RHS of (11) to verify that the coefficient is zero, i.e. that forecasts are unbiased. As shown in Table 1 (Panel A), this yields estimates of the constant and $\delta$ that are insignificantly different from zero, a finding which is consistent with the null of FIRE. A reasonable second step is to introduce additional variables in professional forecasters' information sets to determine whether this information has been fully incorporated in their forecasts, i.e. if forecasts are efficient. Columns (2)-(5) of Panel A in Table 1 present results from using real-time measures of inflation, 3-month Tbills, the change in real oil prices, and the unemployment rate, all lagged one quarter to ensure that these values were available to forecasters. All four variables are statistically significant predictors of ex post mean forecast errors, contrary to the null of FIRE. For three out of four, the coefficient on forecasts also becomes different from zero once these additional variables are included. ${ }^{7}$

Second, even if we observe a rejection of the null hypothesis that is not driven by data-mining, such a rejection is not directly informative about alternative models of the expectations formation process. Does the finding of predictive power from lagged inflation or unemployment point to a rejection of rational expectations and therefore possibly toward models with adaptive expectations or does it point to a rejection of the full-information assumption, as in sticky information or imperfect information models? In the absence of clear theoretical predictions from these models about the estimated coefficients in these empirical specifications, little insight about the expectations formation process is gained from statistical rejections of the null hypothesis.

Third, and most fundamentally, these tests are uninformative about the economic significance of the results. The assumption of FIRE is easy to disprove: as emphasized by Mankiw et al. (2003), the fact

\footnotetext{
7 This selection of variables is not a random sample but rather is deliberately based on previous evidence of departures from the null of FIRE identified in Thomas (1999), Mehra (2002), Mankiw et al. (2003) and Pesaran and Weale (2006).
} 
that economic agents systematically disagree about expected outcomes is inherently inconsistent with all agents knowing the true structure of the model and observing all economic variables and shocks perfectly in real-time. What matters of course for economists is not whether the assumption is literally true, since it clearly is not, but rather whether the deviations from FIRE are significant enough to have important economic implications. The statistical rejection of the null of FIRE arising from the predictability of forecast errors by certain macroeconomic variables over different time periods does not directly shed light as to whether these rejections are economically significant.

Our approach can address most of these concerns. First, because we derive predictions from models of informational rigidities that nest the full-information assumption, we have guidance from the theory as to what the relevant RHS variable should be, namely the revision in forecasts for the relevant time horizon. Thus, the incentive for data-mining is reduced since the relevant RHS variable is motivated by theoretical considerations. Second, there is a well-defined alternative hypothesis from models of informational rigidities given by the prediction that $\beta>0$, as well as additional testable restrictions, which allow us to ascertain whether rejections of the null of FIRE indicate rejections of rationality or of the full-information assumption. Third, because both theoretical models of informational rigidities imply that the coefficient on forecast revisions maps directly into the underlying parameters governing the degree of information rigidity, our approach can recover direct estimates of informational frictions and, hence, can help assess the economic significance of any rejections of the null hypothesis of FIRE.

\subsection{Evidence from U.S. Inflation Forecasts of Professional Forecasters}

As a first step to applying our approach, we again follow most of literature on survey measures of expectations and focus on historical inflation forecasts by U.S. professional forecasters. Both stickyinformation and imperfect information models predict a relationship between the mean ex post inflation forecast errors and the mean inflation forecast revisions such that

$$
\pi_{t+h}-F_{t} \pi_{t+h}=c+\beta\left(F_{t} \pi_{t+h}-F_{t-1} \pi_{t+h}\right)+\varepsilon_{t}
$$

where $\beta>0$ if informational rigidities are present. From 1969-2010, we find $\hat{\beta}=1.23$ (0.50) as shown in Panel B of Table 1. As a result, we can reject the null of FIRE at the $5 \%$ level of statistical significance in a manner that is directly informative about the expectations formation process. First, the rejection of the null goes exactly in the direction predicted by models of informational rigidities, so that this finding presents direct evidence in favor of these models. Second, because $\beta$ maps into the degree of information rigidity from each model, we can extract an estimate of informational frictions: e.g. $\hat{\lambda}=\hat{\beta} /(1+\hat{\beta}) \approx$ 0.55. In the context of sticky-information models, this estimate of $\beta$ would imply that agents update their information sets every six to seven months on average. Alternatively, one can interpret this estimate of $\beta$ under imperfect information models as implying that agents put a weight of less than one-half on new 
information and more than one-half on their previous forecasts. Coibion and Gorodnichenko (2008) find similar, albeit slightly higher, estimates of information rigidity using the conditional response of forecast errors to economic shocks. As documented in theoretical work (e.g., Reis 2009), this magnitude of informational frictions should have important quantitative implications for macroeconomic dynamics. Thus, our approach implies that informational frictions are economically as well as statistically significant. $^{8}$

We can also test a restriction implied by these models, namely that the coefficients on the contemporaneous forecast and on the lagged forecast are equal in absolute value. To implement this additional test, we decompose the forecast revision into two terms as follows

$$
\pi_{t+h}-F_{t} \pi_{t+h}=c+\beta_{1} F_{t} \pi_{t+h}+\beta_{2} F_{t-1} \pi_{t+h}+\varepsilon_{t} .
$$

Under models of informational rigidities, we expect $\beta_{1}>0, \beta_{2}<0$, and $\beta_{1}+\beta_{2}=0$. Estimating equation (13) from 1969-2010, we find $\hat{\beta}_{1}=1.24(0.51)$ and $\hat{\beta}_{2}=-1.27(0.51)$. The signs on both coefficients conform to the theoretical predictions of models of informational rigidities, and we cannot reject the null that the sum of the two coefficients is equal to zero. The results therefore provide additional evidence consistent with the notion that the expectations formation process of professional forecasters is subject to information constraints.

Panel B of Table 1 revisits the predictive power of other lagged variables for ex post mean forecast errors when one accounts for the forecast revisions. The two models of informational rigidities imply that once forecast revisions are included on the RHS of (12), other variables in forecasters' information sets should have no additional predictive power, i.e. forecast revisions are a sufficient statistic for characterizing the predictability of ex post forecast errors. Columns (2)-(5) assess this prediction using the same four variables previously found to have predictive power for ex post forecast errors. For three of the variables, inflation, interest rates and changes in real oil prices, the coefficients are not statistically significant which is consistent with the predictions of models of informational rigidities. The result is, on the other hand, at odds with adaptive expectations: if agents were forming their forecasts of inflation using only past values of inflation, then forecast errors should be predictable using other macroeconomic determinants of inflation. Strikingly, this result obtains despite the fact that we picked these variables specifically because previous work has identified them as variables for which the null of FIRE is rejected. Of course, one should again be wary of placing too much weight on this kind of test. As with tests of FIRE, trying enough RHS variables is bound to lead to a rejection of the null hypothesis.

\footnotetext{
${ }^{8}$ This finding implies that the mean forecast across professional forecasters can be adjusted by the forecast revision to systematically reduce forecast errors. Crowe (2010) shows that the MSE of consensus forecasts could have been reduced by approximately 5\% between 2007 and 2009 by applying this adjustment. However, because forecasters in the SPF do not observe the mean forecast when making their own forecasts, this feature of the data cannot be exploited by forecasters in real-time.
} 
Indeed, we find one such rejection of the null under models of informational rigidities when controlling for lagged unemployment: high unemployment is systematically associated with negative ex post inflation forecast errors even after controlling for the forecast revisions. One interpretation, as with traditional tests of FIRE, is that this finding indicates a direct rejection of models of information rigidities. Another view suggests that this finding could be a statistical anomaly. A third interpretation comes from the fact that regressing ex post forecast errors on unemployment comes close to estimating an expectations-augmented Phillips curve. For example, a New Keynesian-type Phillips curve would relate the difference between current inflation and the current mean forecast of future inflation $\left(\pi_{t}-F_{t} \pi_{t+1}\right)$ to a measure of real economic conditions such as the unemployment rate or the output gap. Because our ex post forecast errors are highly correlated with the gap between current inflation and the forecast of future inflation (correlation of 0.66), this Phillips curve relationship could account for the apparent predictive power of unemployment for ex post forecast errors observed in Table 1 in small samples.

\subsection{Information Rigidities, Model Heterogeneity or Forecast Smoothing?}

The sticky information and imperfect information models both point to a systematic relationship between ex post mean forecast errors and ex ante mean forecast revisions which, at least for professional forecasters, is consistent with historical survey data of inflation expectations. However, differences in the information sets of economic agents need not be the only possible explanation for these patterns. One alternative is heterogeneity in the models used by these agents to process common information and generate forecasts. This alternative includes models with learning, in which agents have different priors about the parameters of the underlying data-generating process (DGP), and models in which agents have different beliefs about the DGP. However, these models are at odds with two stylized facts about professional forecasts. First, model heterogeneity implies that some forecasters should systematically outperform the mean forecast because these agents employ models that are closer to the true DGP than models of other agents. Yet one of the most robust empirical findings from the empirical forecasting literature contradicts this prediction: mean forecasts consistently outperform the forecasts of any individual forecaster (e.g. Bauer et al., 2003). Second, one could imagine a setting in which no model used by forecasters is systematically better than others, but some forecasters have models which better characterize the response of the economy to certain shocks than others, e.g. forecaster A has a good model for oil price shocks while forecaster B has a better model for nominal shocks. In such a setting, the top forecaster after an oil price shock would likely be the agent with the better model of oil price shocks. Given the persistent effects of economic shocks, the top forecaster from one period should then be more likely to have a top forecast in subsequent periods than other forecasters. However, this prediction is also at odds with the empirical evidence: Brian and Molloy (2007) document that top forecasters in one period 
are no more likely to be top forecasters in the next period than others. This mean reversion in the quality of forecasts cannot readily be reconciled with model heterogeneity being the primary source of differences in short-run forecasts across professionals. ${ }^{9}$

A second possibility is that the observed deviations from FIRE reflect objective functions on the part of forecasters that depart from minimizing mean-squared errors. This notion seems particularly probable under the sticky-information interpretation of the results: taken literally, the sticky-information model implies that professional forecasters do not update their forecasts, or incorporate any new information, for extended periods of time. This literal interpretation would seem to be implausible. ${ }^{10}$ On the other hand, one could take a broader view of the model relying on the fact that what professional forecasters do is not just estimate an econometric model every month or quarter and distribute the results; a key service they supply to their clients is a comprehensive overview and interpretation of current macroeconomic developments and possible future outcomes. One could then interpret sticky-information not as the actual rate of information updating but more broadly as the rate at which professional forecasters revise their interpretation of the data.

One could argue that this broader view, while more palatable, is no longer an argument about informational rigidities per se but rather about reputational considerations leading to forecast smoothing by professional forecasters (as in Laster el. (1995)) who would want to provide their clientele with "stories" consistent over time. To see how these reputational considerations could be misinterpreted as informational rigidities, consider a stylized optimization problem for a forecaster $i$ who knows the current full-information rational expectations forecast of a variable $x$ at time $t+j\left(E_{t} x_{t+j}\right)$. The forecaster must choose a current forecast $\left(F_{t}^{i} x_{t+j}\right)$ to minimize the MSE of forecasts subject to a penalty that is increasing in the difference between the current forecast and that of the previous period

$$
\min _{F_{t}^{i} x_{t+j}}\left\{E_{t}\left(x_{t+j}-F_{t}^{i} x_{t+j}\right)^{2}+\alpha\left(F_{t}^{i} x_{t+j}-F_{t-1}^{i} x_{t+j}\right)^{2}\right\} .
$$

This simple setup highlights the conflicting objectives of professional forecasters: providing good forecasts (the first component) while maintaining a consistent story over time (the second term, $\alpha>0$ ). The first order condition with respect to the contemporaneous forecast yields the following relationship between ex post forecast errors and the ex ante forecast revision of the professional forecaster:

\footnotetext{
${ }^{9}$ For longer-horizon forecasts, model-heterogeneity is likely to be more important than individual information sets. For example, long-run unemployment rate forecasts should depend primarily on whether forecasters accord any weight to hysteresis. Similarly, current 2-3 year-ahead inflation forecasts for the U.S. should hinge on whether forecasters use a Keynesian-type model, in which the current large output gaps should point to low inflationary pressures, or a monetarist-type model, in which the expansion of the Fed's balance sheet is likely to presage increased inflationary pressures in the future. Because our focus is on forecasts at relatively short-horizons (up to one year ahead), these considerations are likely to be dominated by informational factors, as documented in the text.

${ }^{10}$ Andrade and Le Bihan (2010) use individual forecasts of professional forecasters in Europe to quantify how frequently forecasters do not change their forecasts at all and find a frequency of updating forecasts of approximately 0.75 per quarter, of which only a fraction is likely to be due to rounding errors.
} 


$$
x_{t+j}-F_{t}^{i} x_{t+j}=\alpha \Delta F_{t}^{i} x_{t+j}+v_{t+h, t}
$$

where $v_{t+h, t}$ is the rational expectations error as defined in (4) and $\Delta F_{t}^{i} x_{t+h}=F_{t}^{i} x_{t+h}-F_{t-1}^{i} x_{t+h}$. Averaged across forecasters, this expression yields an identical relationship between mean forecast errors and forecast revisions as that implied by both sticky information and imperfect information models, but the coefficient on forecast revisions would now be interpreted as the marginal cost of changing the forecasts due to reputational considerations on the part of professional forecasters. Hence, the results in Table 1 could be interpreted as stemming from informational rigidities or from reputational concerns by professional forecasters.

To disentangle these different interpretations of the data, we consider several additional tests of inflation expectations. As a first step, we study forecasts from different types of professional forecasters. The Livingston Survey of Professional Forecasters, a biannual survey first established in 1946 by the columnist Joseph Livingston and maintained since 1990 by the Philadelphia Fed, provides individual inflation forecasts from economists at academic institutions, commercial banks, and non-financial firms, among others. ${ }^{11}$ For each forecaster, the survey includes their forecasts of the CPI in 6 months and in 12 months. $^{12}$ Thus, we can apply our empirical specification at the 6-month forecasting horizon. Table 2 presents the results from 1969 to 2010 for the mean forecasts across all professional forecasters as well as using the mean forecasts across subsets of professional forecasters. Using all forecasters in the Livingston survey, the coefficient on forecast revisions is slightly above one as found using the SPF. There are substantial differences across forecaster types however: academic economists have the smallest estimated coefficient while commercial banks have a significantly higher coefficient estimate than academics. This result is at odds with what one would expect to find if the results were driven by reputational considerations: the forecasts of academics are entirely for external distribution, hence one would expect the reputational considerations to be particularly important for these agents, while forecasts from industry are primarily for internal profit-generating activities such that one would expect reputational factors to be subordinate to minimizing forecasting errors. Because the data point to greater rigidity of forecasts on the part of private industry forecasters than academics, we interpret this finding as more suggestive of informational rigidities than reputational considerations. ${ }^{13}$

As a second step, we consider two additional sources of expectations for which maintaining credibility should play little to no role in determining forecasts: consumer expectations and expectations

\footnotetext{
${ }^{11}$ The categories of forecasters also include investment banks, government forecasters, the Federal Reserve, labor organizations, and "other." We do not look at these in detail because of how few forecasters there are in each of these groups over time. The data is available on the website of the Federal Reserve Bank of Philadelphia.

${ }^{12}$ Forecasts are of the seasonally-unadjusted CPI prior to December 2004 and seasonally adjusted thereafter.

${ }^{13}$ Private sector forecasts could still be subject to reputational considerations within the firm (i.e. if forecasters need to defend their forecasts to other individuals in the firm) but these considerations should probably be less important than reputational considerations pertinent to forecasts aimed at the general public.
} 
derived from asset prices. For the former, we rely on the Michigan Survey of Consumers. Each month, the University of Michigan surveys 500-1,500 households and asks them about their expectation of price changes over the course of the next year. For the latter, we use the inflation expectations data from the Cleveland Fed based on the method developed in Haubrich, Pennacchi and Ritchken (2008) who rely on the term structure of interest rates and inflation swaps to extract measures of market expectations of CPI inflation at multiple yearly horizons starting in 1982. Both market-based and consumer expectations of inflation should be independent of reputational considerations (anonymous forecasts for consumers; money on the table for asset prices) and therefore should help distinguish between informational rigidities and forecast smoothing arising from concerns about maintaining credibility. Figure 1 plots these two sets of inflation forecasts, as well as the corresponding year-ahead CPI inflation forecasts from the Survey of Professional Forecasters. All three series are highly correlated, but the financial market and professional forecasts exhibit particularly strong comovement.

Table 3 presents the root mean squared forecast errors from 1982 to 2009 for all three forecasts. The Survey of Professional Forecasters has the smallest MSE, although the difference with respect to market-based forecasts is not statistically significant. Nonetheless, if professional forecasts were smooth because of reputational considerations, one would expect these forecasts to be worse on average than market-driven expectations. Ang et al. (2007) similarly find that professional forecasts outperform a variety of model-based forecasts, asset-pricing implied forecasts and consumer forecasts. Table 3 also presents results of regressions designed to assess the information content of each type of forecast. Specifically, we regress ex post CPI inflation on the ex ante forecasts. When both professional forecasts and consumer forecasts are included, the coefficient on professional forecasts is large, statistically significantly different from zero but not from one, while that on consumer forecasts is small and not statistically different from zero. Hence, there appears to be little additional informational content in consumer forecasts relative to professional forecasts. When this exercise is repeated with market-based expectations of inflation in place of consumer forecasts, the results are even more pronounced. Again, this result is inconsistent with reputational considerations accounting for smooth forecasts on the part of professional forecasters since one would then expect market-based and possibly consumer forecasts to have significantly more explanatory power than professional forecasts.

We can also estimate the coefficient on forecast revisions for each type of forecast to assess whether this coefficient is significantly lower for consumers and market-based forecasts, as would be expected if reputational concerns account for smoothing on the part of professional forecasters. However, because the Michigan Survey of Consumers as well as the market-based expectations are only available at a forecasting horizon of one year, we replace the forecast revision with the change in the year-ahead forecast, yielding the following specification 


$$
\pi_{t+4, t}-F_{t} \pi_{t+4, t}=c+\beta\left(F_{t} \pi_{t+4, t}-F_{t-1} \pi_{t+3, t-1}\right)+\varepsilon_{t}
$$

where $\pi_{t+4, t}$ denotes the inflation rate between $t+4$ and $t$. In this case, the error term will consist of the rational expectations forecast error, as in equation (12), and $\beta\left(F_{t-1} \pi_{t-1}-F_{t-1} \pi_{t+3}\right)$ because the forecasts do not have perfectly overlapping time horizons across periods. As a result, this specification cannot be estimated by OLS. Instead, we estimate this specification by GMM, using as instruments innovations to oil prices at time $t .^{14}$ These innovations are valid instruments because they are uncorrelated with both past information ( $t-1$ and earlier) as well as the rational expectations error. Furthermore, because oil prices have significant effects on CPI inflation, these should be instrumental variables with the desired properties. As illustrated in Table 4, these oil price innovations are statistically significant predictors of contemporaneous changes in inflation forecasts for all three measures of inflation expectations and can account for an important share of their volatility. Applying this estimation approach to a common time sample of 1982 to 2009, we find a coefficient on forecast revisions of 1.3 for professional forecasters, a finding that closely mirrors our previous results. For consumers, the point estimate is smaller but also highly statistically significant which conforms to the findings of Coibion and Gorodnichenko (2008). For market expectations, the point estimate is even higher than for professional forecasters, but it is also less precisely estimated which is likely a result of the reduced predictive power of oil price innovations on market-based forecast revisions. As with the previous tests, the evidence continues to point primarily toward informational rigidities as the likely source of the positive coefficient on forecast revisions rather than reputational considerations since we find qualitatively similar results for consumers and market-based forecasts as with professional forecaster data. ${ }^{15}$

\subsection{Pooled U.S. Evidence on Informational Rigidities among Professional Forecasters}

While much of the empirical literature on the expectations formation process has focused on inflation forecasts, our approach is readily applicable to different macroeconomic variables. Furthermore, we can

\footnotetext{
${ }^{14}$ Specifically, we run an AR(2) on the first difference of the log of nominal oil prices and define the residuals as oil price innovations.

${ }^{15}$ There are two other pieces of evidence favoring an information rigidity interpretation of the coefficient on forecast revisions. First, as presented in section 4.1, the cross-sectional heterogeneity in coefficients on forecast revisions across countries and macroeconomic variables can be well-accounted for using the predicted determinants of imperfect information models. Second, the observational equivalence of the relationship between ex post mean forecast errors and ex ante mean forecast revisions in models of informational rigidities versus forecast smoothing motives obtains only when the forecast smoothing is modeled in a static fashion. In general, if forecasters wish to minimize changes in their forecasts, then they will also take into account the fact that the current choice of their forecast will affect the cost of changing forecasts next period. If one includes this dynamic element, ex post forecast errors should depend positively on the current forecast revision but also negatively on the expected forecast revision in the next period, i.e. $E_{t} x_{t+h}-F_{t} x_{t+h}=\alpha\left(F_{t} x_{t+h}-F_{t-1} x_{t+h}\right)-\alpha \beta\left(E_{t} F_{t+1} x_{t+h}-F_{t} x_{t+h}\right)$. This specification can be estimated by GMM after substituting ex post values for ex ante expectations under the null of fullinformation rational expectations. Empirical estimates of this augmented specification using SPF forecasts consistently yield positive estimates on future forecast revisions, with varying degrees of statistical significance, which is inconsistent with the sign restrictions imposed by the dynamic forecast smoothing model.
} 
also exploit the multiple forecasting horizons available in the data to further expand the power of our tests. In this section, we apply our method to professional forecasts for a multitude of macroeconomic variables and forecasting horizons.

As a first step, we exploit the fact that the Survey of Professional Forecasters (SPF) contains quarterly forecasts for four additional macroeconomic variables going back to 1968Q4: besides the GDP price deflator, these include real output, industrial production, housing starts, and the unemployment rate. $^{16}$ Furthermore, each of these variables is available at multiple forecasting horizons, ranging from forecasts of the current quarter to 4 quarters ahead. To exploit this additional dimension, we utilize each of the individual quarterly forecasting horizons in our estimation. Thus, we estimate a pooled regression

$$
x_{i, t+h}-F_{t} x_{i, t+h}=c+\beta \Delta F_{t} x_{i, t+h}+\varepsilon_{i, h, t}
$$

where $x_{i}$ indicates which macroeconomic variable is included and $h$ denotes the specific forecasting horizon ranging from 0 (forecasts of the current quarter) to 3 (forecasts for 3 quarters ahead). We consider direct estimates of equation (14) as well as estimates augmented to include cross-sectional and time fixed effects. While the SPF includes forecasts up to 4 quarters ahead, the horizon is limited to 3 quarters in the empirical specification because forecast revisions call for an additional forecasting horizon, e.g. when $h=3$, the forecast revision is $F_{t} x_{i, t+3}-F_{t-1} x_{i, t+3}$. To construct forecast errors, we use real-time values available one year after the relevant time horizon. For the first three series, forecasts of annualized quarterly percent changes are constructed from the underlying mean forecasts of the levels. Table 5 presents the results of this pooled regression over 3,240 observations as well as when we include cross-sectional fixed effects (for both the forecasting horizon and macroeconomic variable) and both cross-sectional and time fixed effects. ${ }^{17}$ In each case, the estimate of $\beta$ is positive and statistically significant so that we can reject the null of FIRE in exactly the direction predicted by models of informational rigidities. The point estimates of $\beta$ imply that the average duration between information updates is four months (in the context of sticky-information models) or that new information moves forecasts by $70 \%$ of what it would be under full-information (in the context of imperfect information models). The standard errors are now smaller than when the degree of information rigidity was based only on forecasts of one-year ahead inflation rates, which reflects the increased precision arising from

\footnotetext{
${ }^{16}$ Output is measured by GNP prior to 1992 and GDP thereafter. The price deflator is the implicit GNP deflator before 1992, implicit GDP deflator from 1992 to 1996, and the chained GDP deflator thereafter. The SPF also includes historical forecasts of corporate profits. However, the quality of this data is much worse than for other variables, reflecting sensitivity to factors like TVA adjustments. Private communications with Tom Stark, the manager of the SPF dataset, confirmed that individuals often report forecasts of corporate profits using definitions at odds with the SPF definition, so that mean forecasts are excessively volatile as a result of measurement issues.

${ }^{17}$ For each pooled dataset, we identify and remove outliers using jackknife and Cook's distance. Removing outliers makes estimates more stable and precise. The qualitative results do not change when outliers are not removed.
} 
pooling across multiple macroeconomic variables and forecasting horizons. ${ }^{18}$ Furthermore, when we decompose the forecast revision into two components, the contemporaneous forecast and the lagged forecast, as in equation (13), each coefficient is of the sign predicted by theoretical models of informational rigidities and we cannot reject the null hypothesis from these models that the sum of the two coefficients is equal to zero at the five percent level of statistical significance.

Starting in 1981, the SPF includes forecasts of 8 additional macroeconomic variables: the 3month Treasury bill (Tbill) rate, the AAA interest rate, real consumption expenditures, real residential investment, real non-residential investment, real federal government expenditures, real state/local government expenditures, and the overall CPI. For each NIPA series and CPI inflation, we construct forecasts of annualized quarterly percent changes and use real-time data to construct forecast errors, while the two interest rates are measured in levels. The forecast horizons again run from $h=0$ to $h=3$. Thus, pooling across all of the variables available in the SPF since 1981 and all forecasting horizons yields 5,793 observations. The results from estimating equation (14), presented in Table 5, again point to an estimate of $\beta$ which is positive and statistically different from zero, whether or not fixed effects are included. The point estimate is larger than in the previous case, pointing to average durations between information updates of approximately five months in the context of sticky information models, or a weight of $60 \%$ being assigned to new information in the formation of forecasts in the context of imperfect information models. Furthermore, a decomposition of the forecast revision into current versus lagged forecasts again yields the result predicted by models of informational rigidities that we cannot reject the sum of the two coefficients being equal to zero nor can we reject the sign restrictions implied by these models.

\subsection{Cross-Country Evidence on Informational Rigidities among Professional Forecasters}

In addition to the U.S. Survey of Professional Forecasters, we have constructed a dataset of quarterly forecasts from the international survey of professional forecasters done by Consensus Economics. This dataset covers twelve countries: the G-7 countries of U.S., U.K., France, Germany, Italy, Japan and Canada as well as Spain, Norway, the Netherlands, Sweden and Switzerland. ${ }^{19}$ Data for the G-7 countries spans 1989 to 2010 while data for other countries begin primarily in $1994 .^{20}$ For each country, forecasts for five macroeconomic variables are available: consumer price inflation, real GDP growth, interest rates,

\footnotetext{
${ }^{18}$ Because the errors are likely to be correlated over time as well as across macroeconomic variables and forecasting horizons, we use Driscoll-Kraay (1998) standard errors which are robust to both time and cross-sectional correlation of the error terms.

${ }^{19}$ Consensus Economics provides forecasts for many more countries than the twelve included in our sample, often at the monthly frequency, but these forecasts are restricted to the calendar year time horizon. While our method is well-suited to these fixed forecasting horizons, we focus on this restricted set of countries because of the larger set of forecasting horizons available.

${ }^{20}$ Forecasts for Norway and Switzerland only become available in 1998.
} 
industrial production growth and real consumption growth. Forecasts are available for the current quarter and for the subsequent 5-6 quarters. As a first step, we estimate the average degree of information rigidity pooled across all macroeconomic variables, countries and forecast horizons, i.e.

$$
x_{i, j, t+h}-F_{t} x_{i, j, t+h}=c+\beta \Delta F_{t} x_{i, j, t+h}+\varepsilon_{i, j, h, t}
$$

where $i$ denotes the macroeconomic variable, $j$ the country and $h$ the forecasting horizon. Based on 22,347 observations, the results again point to an estimate of $\beta$, presented in Table 5 , that is positive and statistically significant, confirming our finding from U.S. professional forecasters. This occurs when equation (15) is estimated by OLS or including cross-sectional fixed effects for different countries, variables, and forecasting horizons, as well as with both cross-sectional and time fixed effects. The implied degree of information rigidity is very close to the estimates for the U.S. using the wider set of variables from 1982 to 2010. When we decompose the forecast revision (Panel B), each coefficient has the same sign as predicted by models of informational rigidities and we again cannot reject the null hypothesis that the sum of the two coefficients is equal to zero at the five percent level of statistical significance.

In addition, we consider country-specific estimates of the degree of information rigidity, pooled over macroeconomic variables and forecasting horizons. Figure 2 plots the resulting estimates of $\beta$ for each country. The countries with the highest degrees of informational rigidities are Spain and Sweden, while the lowest are Canada and Norway. All of the estimates are statistically significantly positive so we can reject the null of FIRE for every country and this rejection of the null goes exactly in the direction predicted by models of informational rigidities. The substantial cross-country heterogeneity in information rigidity, ranging from estimates of 0.3 for Canada to almost one for Spain, point to a potential role for policy and institutions in determining country levels of information rigidity, an issue to which we return in section 4.2 .

\section{Determinants of Informational Rigidities}

The empirical results pooled across macroeconomic variables and forecasting horizons are strongly supportive of models with informational frictions: the estimated coefficients on forecast revisions are consistently positive as predicted by these theories and large enough to affect macroeconomic dynamics. Given these findings, we turn to the question of differentiating between sticky information and imperfect information models of the expectations formation process, as well as evaluating the underlying macroeconomic and policy determinants of informational rigidities.

\subsection{Differentiating by Forecast Horizon and Forecasted Variable}

In the sticky-information model of Mankiw and Reis (2002) and Reis (2006), firms update their information sets infrequently, but when they do so, they acquire full-information rational expectations. 
As a result, there is a single parameter governing the frequency of updating information which is common across macroeconomic variables and forecasting horizons. Thus, a testable implication of the stickyinformation model is that the estimated degree of information rigidity is invariant to the forecasting horizon and the variable being forecasted. In imperfect information models, on the other hand, the coefficient on forecast revisions for a given macroeconomic variable will be governed by the Kalman gain associated with that variable, which will depend on factors such as the persistence of the series and the strength of the signal observed with respect to that macroeconomic variable. The signal-noise ratio could vary across variables for a variety of reasons, such as the magnitude of data revisions and the frequency of data releases. Both factors would affect the strength of the signal observed for a macroeconomic variable when forecasts are done at the quarterly frequency. One way to assess the relative merits of these two models in accounting for the expectations formation process of professional forecasters is therefore to compare the estimated degrees of information rigidity across macroeconomic variables being forecasted as well as across forecasting horizons.

We provide two decompositions of our pooled estimates from each dataset: one by forecasting horizon (left column of Figure 3) and one by macroeconomic variable (right column of Figure 3). For the U.S. SPF, we cannot reject the null hypothesis of equal coefficients across forecasting horizons, as predicted by both models of informational rigidities for quarterly forecasts ( $p$-values of 0.15 and 0.23 for 1968 variables and 1981 variables respectively), but we can strongly reject ( $p$-value $<0.001$ ) the null of equality across macroeconomic variables for the thirteen variables available since 1981 and weakly so for the five variables available since $1968(p$-value $=0.06)$. With the cross-country Consensus Economics data, we can again strongly reject the null of equality across macroeconomic variables $(p$-value $<0.001)$ and, unlike with the U.S. SPF data, we can also strongly reject the null of equality across forecast horizons ( $p$-value $<0.001)$.

One clear result is that the degree of information rigidity is not equal across macroeconomic variables: an implication at odds with sticky-information models. On the other hand, the fact that heterogeneity in information rigidity exists across macroeconomic variables does not imply that imperfect information models can account for this cross-sectional variation. In the simple imperfect information model of section 2.2, the degree of information rigidity depends on the Kalman gain, which is a function of the persistence of the underlying macroeconomic process as well as the precision of the signal received by economic agents. More persistent processes imply, holding all else constant, that agents should pay more attention to current signals since forecast errors for a persistent process convey more information about the future than when the underlying process is less persistent. A more precise signal naturally implies that agents should place relatively more weight on the current signal than on past forecasts. Thus, 
imperfect information models imply that the degree of information rigidity should be decreasing in the persistence of the series being forecasted and increasing in the amount of noise in the signal.

To assess these predictions, we construct measures of each as follows. First, for each country $j$ and macroeconomic variable $i$ in the Consensus Economics survey of professional forecasters, we fit an autoregressive process which yields an estimate of both the persistence of the variable $\left(\rho_{i, j}\right)$ and the volatility of its innovations $\left(\sigma_{i, j}\right)$. Second, we generate a measure of the noise associated with each series from a) the standard deviation of revisions to this series or b) the standard deviation of forecast disagreement for this series. ${ }^{21}$ Third, we construct a measure of the noise-signal ratio $\left(\kappa_{i, j}\right)$ by taking the ratio of a measure of the noise to the standard deviation of the innovations to the variable from the first step. Given these measures of the predicted determinants of information rigidity, we assess their importance by regressing our estimates of the coefficients on forecast revisions for each countrymacroeconomic variable pair, pooled across forecasting horizons, in the cross-country Consensus Economics dataset set

$$
\beta_{i, j}=c+\gamma_{1} \rho_{i, j}+\gamma_{2} \kappa_{i, j}+\text { error }_{i, j}
$$

where $i$ denotes a specific variable, $j$ denotes the country, and $\beta_{i, j}$ is the estimated coefficient on forecast revisions for each country-variable pair in the cross-country data-set. ${ }^{22}$

The results are presented in Table 6 . The coefficients on the persistence are consistently negative across specifications. When using the noise-signal ratio measured using data-revisions (i.e. exploiting only common sources of noise), the coefficient is positive, as expected, but not significantly different from zero. Appendix Figure 1 shows that this is sensitive to outliers. As a result, we also consider estimates of (16) based on robust S-regressions, which automatically identify and account for outliers, and the results point to a positive and statistically significant effect of the noise-signal ratio, as predicted by the imperfect information model. Simply dropping the outliers identified by the S-regression leads to similar results. When we use the cross-sectional dispersion of forecasts, which includes both common and idiosyncratic information among forecasters, to measure noise, the coefficient on the noise-signal ratio of each country-variable pair is positive and statistically significant whether or not we control for outliers. Strikingly, this simple specification can account for about 20-30 percent of the heterogeneity in informational rigidities. Thus, not only are the theoretical predictions of imperfect information models

\footnotetext{
${ }^{21}$ Specifically, for each time period, we take the difference between measures of the variable available two quarters and four quarters later, then compute the standard deviation of these revisions across the entire sample. Alternative time horizons for measuring revisions yield the same qualitative results. Real-time data, including revisions over the course of a year, are included in the Consensus Economics dataset. Data on cross-section dispersion of forecasts (forecast disagreement) are available for the growth rate of GDP, consumption and industrial production as well as inflation.

${ }_{22}$ Because the cross-section of forecasted macroeconomic variables in the U.S. Survey of Professional Forecasters is relatively small (13 variables consistently available since 1981), we only apply this analysis to the cross-country data.
} 
qualitatively consistent with the observed heterogeneity in informational rigidities across countries and variables, but this model can also quantitatively account for a considerable share of the observed crosssectional variation.

The fact that we can reject the null of equality across forecast horizons using the Consensus Economics data but not for the U.S. SPF is also useful to differentiate between the models. As presented in Section 2, both models predict that the estimated coefficient on forecast revisions should be identical for different forecasting horizons when forecasts are for quarterly changes. However, the forecasts of GDP, consumption and industrial production growth in the Consensus Economics survey are for year-onyear percent changes, and the inflation rate is measured by year-on-year percent changes in the price level. This distinction makes no difference under sticky-information, and the prediction remains that the coefficient on forecast revisions be equal across forecasting horizons, contrary to what we observe in the data. For imperfect information models, on the other hand, this distinction is important. Consider, for example, the forecast for the current quarter year-on-year GDP growth: the forecasters have observed values for at least two, and likely three, of the four quarters over which they are forecasting. Hence, they have already received very strong signals about the value of current year-on-year GDP growth. When, on the other hand, they must forecast year-on-year GDP growth in four quarters, they will not have observed any of the quarterly values over which the forecast is made and therefore the available signals will be much weaker. Thus, the strength of the signal is falling over the first four forecasting horizons ( $h=0$ to 3) so that one would expect the estimated coefficient on forecast revisions to be rising over these horizons, which is exactly the pattern observed in Figure $3 .^{23}$ We have verified in Monte Carlo simulations of the imperfect information model in section 2.2 that this feature of the Consensus Economics surveys can indeed account for the rising estimated coefficients across forecasting horizons. Further evidence that the large increase in estimated coefficients with the forecasting horizon is driven by this feature of the Consensus Economics forecasts is that, if we estimate the coefficient on forecast revisions at different horizons specifically for interest rate forecasts, which are not measured in year-onyear changes, the rising pattern of estimated coefficients is substantially dampened.

\footnotetext{
${ }^{23}$ The drop in the estimated coefficients at longer forecasting horizons in Figure 2, which occurs in both the SPF and Consensus data, appears to be driven entirely by finite sample issues combined with some variables not being very persistent. This is because, with low persistence, forecasts of distant values will be near constant, so that contemporaneous forecast revisions will have very little explanatory power for ex post forecast errors, pushing the estimated coefficient toward zero in small samples. This is true under both sticky-information and imperfect information models and is thus not informative about the relative merit of the two approaches. We have verified in Monte Carlo simulations that this persistence issue can reproduce the observed decline in estimated coefficients in Figure 2. Furthermore, when we reproduce the decomposition across forecasting horizons for variables measured in changes (GDP growth, consumption growth, etc) which are not very persistent versus those variables measured in levels which are much more persistent on average, we find that the decline in estimated coefficients at longer forecasting horizons is non-existent for the latter but particularly pronounced for the former. Results are available upon request.
} 


\subsection{Policy and Institutional Determinants of Information Rigidity}

The previous section presents evidence that the varying degrees of information rigidity associated with macroeconomic variables are well-explained by the persistence and noise-signal ratios of these variables. However these determinants are themselves functions of policy and institutional characteristics. In this section, we consider the possible effect of three sets of monetary policy institutions and actions on the degree of information rigidity. First, we assess whether informational rigidities in the U.S. changed with the onset of the Great Moderation, the dramatic decline in macroeconomic volatility commonly associated with the monetary policy changes enacted under Fed Chairman Paul Volcker. Second, we assess to what extent the independence of the central bank affects the expectations formation process across countries. Third, we consider whether the official adoption of inflation targeting by central banks affects the degree of information rigidity in inflation forecasts.

\subsubsection{Great Moderation}

McConnell and Perez-Quirós (2000) and others have documented a substantial decrease in macroeconomic volatility both in the U.S. and other developed countries since the early to mid-1980s. Figure 4 plots the time-varying standard deviation of real GDP growth for the U.S., for example, which is rising throughout the 1970 s, peaks in the very early 1980s, then exhibits a very sharp decline in the mid1980 s, declining by more than half relative to the average level during the 1970s. While the source of this phenomenon remains a point of contention, one prominent explanation emphasizes the changes in monetary policy put in place under Volcker, either in terms of a stronger endogenous response to macroeconomic fluctuations as in Clarida et al. (2000) or because of the Volcker disinflation as in Coibion and Gorodnichenko (2009). At the same time, there is only mixed evidence that microeconomic volatility declined over this time period. For example, Davis et al. (2006) report that the volatility of employment has fallen since the 1970s for non-publicly traded firms while Comin and Mulani (2004) and Comin and Philippon (2005) show that volatility increased for publicly traded firms over the same period. Furthermore, volatility at the household level appears to have been trending up over time (see Davis and Kahn (2008) for a review). As a result of the reduction in the volatility of macroeconomic variables relative to microeconomic variables, one might expect that economic agents would choose to allocate relatively more resources to tracking micro rather than macro-level shocks since these shocks become quantitatively more important for profits and utility. Thus information rigidity should have increased with the arrival of the Great Moderation.

To explore this hypothesis, we estimate equation (10) for each quarter separately using SPF data and then compute non-parametrically a local average of the estimated $\beta$ 's for each period to provide a sense of the low frequency variation in the degree of informational rigidities. Figure 4 plots the dynamics 
of the local averages of $\beta$ as well as associated standard errors. The figure shows that informational rigidities were falling from the late 1960s to the early 1980s as the volatility of macroeconomic variables was rising. ${ }^{24}$ The minimum level of information rigidity is reached in 1983-84, which closely matches the start of the Great Moderation identified in McConnell and Perez-Quirós (2000), and since then, the estimated degree of information rigidity has consistently been increasing. The changes in the level of informational rigidities over time are statistically and economically significant, especially when one compares mid-1980s and in late 2000s.

This significant low-frequency variation in the estimated coefficients on forecast revisions suggests that one should be wary of treating informational rigidities at the macroeconomic level as a structural parameter since these rigidities can vary over time in response to changes in macroeconomic conditions. Specifically, more tranquil times should be ceteris paribus associated with greater informational rigidities. However, the rising degree of inattention over the course of the 1990s and 2000s implies that the same sized shock would have larger real effects towards the end of the sample because informational rigidities, like nominal rigidities, amplify the response of the economy to a given set of shocks. Thus, this observation suggests an additional mechanism, along with increased risk-taking on the part of financial market participants, through which the Great Moderation may have contributed to the severity of the Great Recession. ${ }^{25}$

\subsubsection{Central Bank Independence}

The evolution of U.S. monetary policy under Volcker can be characterized as a change in the policy rule decided upon internally by members of the FOMC. To the extent that that this reform contributed to the Great Moderation, it appears to have had large effects on the degree of information rigidity faced by economic agents. But people's incentive to allocate resources to keeping track of macroeconomic conditions also depends on the institutional characteristics of the central bank. For example, in the seminal Barro and Gordon (1983) exposition of the time inconsistency problem, the inflation bias associated with discretionary monetary policy hinges upon the central bank's target unemployment rate being less than the natural rate of unemployment. This policy objective is more likely to occur when central banks are subject to the influence of elected officials whose job security hinges disproportionately on the state of the real economy. As a result, minimizing this influence by making central banks more

\footnotetext{
${ }^{24}$ Although we do not have SPF forecast data before 1968, we conjecture that the relatively high informational rigidities in the late 1960s can be explained by the relatively tranquil period experienced by the U.S. economy during the 1960s.

${ }^{25}$ The figure also suggests that the high volatility of the 1970s led to a gradual increase in attention on the part of economic agents, making the economy become progressively less sensitive to any given shock. This decline in information rigidity may therefore also have contributed to onset of the Great Moderation. More generally, the figure points to the possibility of low-frequency cycles in volatility arising from the endogenous response of information rigidities to volatility and the feedback effect of changing information rigidity on volatility.
} 
independent of elected officials has been one of the defining institutional reforms of central banks pursued by numerous developed and developing countries alike.

With greater central bank independence and the associated reduced incentives by this institution to deviate from pre-announced policies, the incentive of economic agents to closely monitor the actions of the central bank and macroeconomic conditions more generally should be reduced. Consequently, if central bank independence is effective, one of the metrics along which one should be able to quantify this success is via its effect on the degree of information rigidity associated with the expectations formation process of economic agents. Because our approach allows us to directly quantify the latter, it provides a novel dimension to assess the efficacy of this institutional characteristic. To quantify the degree of central bank autonomy, we use the measure constructed by Arnone et al. (2007). Each country's score, between 0 and 1 , reflects a combination of the degree of political autonomy (which measures the involvement of the government in selecting governors and directors of the central bank as well as the ability of the central bank to implement its desired policies without government approval) and economic autonomy (which measures operational autonomy, such as how involved the central bank is in purchasing government debt) as of 2003. The twelve countries in our Consensus Economics data vary substantially in terms of their scores, with Japan having the lowest rating of 0.44 (driven mainly by a very low political autonomy rating) while Sweden, Switzerland and France have the highest scores (0.94). ${ }^{26}$ The U.S. has the fourth lowest rating in this sample of countries (tied with Norway) primarily because of a low political autonomy score.

To quantify the effect of central bank independence on the expectations formation, we regress our country-specific estimate of the coefficient on forecast revisions (as in Figure 2) on each country's central bank independence rating. Figure 5 presents a scatter plot of these data. There is a strong positive relationship between central bank independence and the country-specific estimate of the coefficient on forecast revisions, although Japan appears to be a clear outlier because of its central bank's weak political independence. Using a Huber robust regression, which controls for outliers, we can reject the null of no relationship between central bank independence and information rigidity at standard levels of statistical significance. However, the quantitative implications of central bank independence for the expectations formation process are likely to be limited: given the estimated slope, if the U.S. were to achieve the same level of central bank independence as Sweden, the change in information rigidity would be equivalent to an increase in the average duration between information updates of half a month in the context of stickyinformation models.

\footnotetext{
${ }^{26}$ Countries in the Euro-area do not have the same ratings because of the different procedures they use in determining who will be appointed to the ECB governing board, among other political autonomy factors.
} 


\subsubsection{Inflation targeting}

Another policy which has received particular attention is inflation targeting, or the official commitment by a central bank to achieving a numerical target for the inflation rate over some time horizon. This mechanism, if credible, should lead to a reduction in both the level and the volatility of inflation. The latter implies that, with increased stability, economic agents should devote fewer resources to forecasting inflation. As a result, an implication of credible inflation-targeting regimes should be increased inattention to inflation on the part of forecasters, thereby generating "anchored" expectations. For example, in an extreme case of perfect targeting, all volatility in the inflation rate would be eliminated and therefore economic agents should not allocate any attention to this variable.

However, previous work has had to rely on indirect methods to assess the anchoring of expectations. For example, Levin et al. (2004) find that in countries without an explicit inflation target, private sector inflation forecasts at horizons up to 10 years are significantly correlated with a three-year moving average of lagged inflation, but this correlation is largely absent from the five IT countries in their sample. Similarly, Gürkaynak et al. (2006) find that long-horizon market-based inflation forecasts were invariant to domestic economic news in the UK and Sweden after these countries adopted inflationtargeting, but that this was not the case in the UK prior to adopting inflation-targeting or in the U.S., which has never officially adopted an inflation target While indicative of a qualitative effect of inflationtargeting, these methods cannot directly assess the quantitative implications of inflation-targeting on the expectations formation process. Our approach, on the other hand, can readily be applied to study the effect of this type of policy on the expectations formation process with a firm theoretical footing, To do so, we can relate ex post inflation forecast errors to ex ante forecast revisions augmented with a timedummy for inflation-targeting and an interaction term

$$
\pi_{i, t+h}-F_{t} \pi_{i, t+h}=c+\beta \Delta F_{t} \pi_{j, t+h}+\gamma\left(\Delta F_{t} \pi_{j, t+h} \times I T_{j, t}\right)+\alpha I T_{j, t}+\text { error }_{j t},
$$

where $j$ and $t$ index countries and time, $\pi$ is the inflation rate, IT is a dummy variable equal to one if a country targets inflation at time $t$ and zero otherwise, and $\gamma$, the coefficient on the interaction term, will measure the change in information rigidity associated with inflation targeting, if any. This specification thus allows one to assess not just the possibility that inflation-targeting affects the expectations formation process but also quantify the effect of the policy in terms of its effects on the degree of information rigidity.

Within our cross-country sample, there is a set of countries who became unambiguous inflation targeters over the course of time sample: the Bank of Canada officially adopted inflation-targeting in February of 1991, the Bank of England in October of 1992, the Swedish Riksbank in Janurary of 1993, 
the Spanish Banco de Espana in January of 1995 and the Norwegian Norges Bank in March of $2001 .^{27}$ However, other countries in the dataset are close to being inflation-targeting regimes. For example, the European Central Bank (ECB) has an official inflation target of less than, but close to, $2 \%$ a year but, because it also has other objectives, is not as clear a case of an inflation-targeting regime as the first group. If the ECB is included as an inflation-targeting regime, then all of the countries joining the Euroarea in 1999 can be viewed as adopting an inflation target. Other countries are also sometime considered de facto inflation targeters. Germany, prior to the Euro, and Switzerland have been officially targeting monetary aggregates since the late 1970s, but Bernanke and Mishkin (1997) argue that they should best be thought of as hybrid inflation-targeting regimes. Similarly, while the Federal Reserve is legally subject to the dual mandate and has never officially acknowledged an official inflation target, it is frequently viewed as a de facto inflation-targeting regime. ${ }^{28}$ In light of the de jure versus de facto distinction, we consider three definitions of a country targeting inflation: $i$ ) narrow which covers only countries officially declaring inflation targeting; ii) broad which includes countries in the narrow definition and countries implementing inflation targeting de facto (i.e., Euro area, USA, Germany and Switzerland); iii) intermediate which consists of countries in the narrow definition and countries in the Euro area. ${ }^{29}$

Results reported in Table 7 suggest that there is no robust evidence that inflation targeting leads to greater information rigidity with respect to the inflation rate, regardless of whether we apply a narrow or broad definition of inflation-targeting. While the point estimates of $\gamma$ are consistently positive, such that inflation-targeting leads to higher degrees of inattention, none are statistically different from zero at the five percent level. Only in the case of the intermediate definition, i.e. including official inflationtargeting regimes and the $\mathrm{ECB}$, is the estimate significant at the ten percent level. Importantly, the point estimates of $\gamma$ are all small, on the order of 0.1 . This finding implies that, even if these coefficients were statistically significant, the implied effect on informational rigidities would not be economically large. As a result, there is little evidence that inflation-targeting has had important effects on the expectations formation process among these countries. ${ }^{30}$

\footnotetext{
${ }^{27}$ See Little and Romano (2008) and Roger (2010) for detailed lists of inflation-targeting countries.

${ }^{28}$ For example, a special survey question in the 2007Q4 Survey of Professional Forecasters asked respondents whether they believed that the FOMC had an unofficial inflation target. Approximately half of the respondents answered yes.

${ }^{29}$ The only country which does not qualify as inflation-targeting at some point in time under the broad definition is Japan. However, even this case is ambiguous: Little and Romano (2008) classify Japan as a hybrid inflation-targeter as of March 2006.

${ }^{30}$ There are several reasons why our results differ from previous findings. First, we focus on relatively short-run forecasting horizons, while Levin et al. (2004) and Gürkaynak el al (2006) emphasize the effects of inflationtargeting on long-run inflation expectations. Second, Capistran and Ramos-Francia (2010) argue that the full effect of inflation-targeting on expectations, which they measure via dispersion of forecasts, is not observed until three years after implementation, whereas we assume that the effect is immediate. Nonetheless, our results are consistent
} 


\subsection{State-Dependence in informational rigidities}

Figure 4 documents important low-frequency time variation in the degree of information rigidity for the U.S. consistent with the large changes in macroeconomic volatility observed over this time period. This finding points to the possibility that the acquisition of processing of information may be more statedependent than commonly assumed. In this section, we investigate whether informational rigidities exhibit state dependence over the course of the business cycle as well as in response to a large, visible shock at the aggregate level.

\subsubsection{Information rigidity over the business cycle}

Our results in the previous section indicate that calm times are associated with stronger informational rigidities. In light of this evidence, one may expect that recessions, as periods of increased volatility, should be times when economic agents update and process information faster than in expansions since the (relative) cost of ignoring macroeconomic shocks in recession rises. Gorodnichenko (2008), for example, shows in a theoretical model that the acquisition of information endogenously increases shortly after the occurrence of an aggregate shock as economic agents face increased uncertainty about the current state of the economy and consequently find it beneficial to devote more resources to learning about current macroeconomic conditions. Using estimates of $\beta$ computed for each quarter separately as in the previous section, we consider the following econometric specification

$$
\beta_{t}=\alpha+\sum_{j}^{J} \phi_{j} I_{t-j}^{R E C}+\text { error }_{t},
$$

where $I_{t}^{R E C}$ is a dummy variable equal to one in the first quarter of each recession, as identified by the NBER, and zero otherwise. By varying index $j$, we construct a sequence of estimated $\phi_{j}$ which may be interpreted as an impulse response of informational rigidities to a recession. To smooth the path of coefficients $\phi_{j}$, we fit a polynomial distributed lag model with the polynomial order equal to 4 and $J=20$. Figure 6 shows the path of the estimated $\phi_{j}$ over four years after the economy slides into a recession. We assume that the economy starts at an average level of information rigidity which is equal to $\hat{\alpha}$. At the start of a recession, informational rigidities are and remain relatively high. However, as time passes, informational rigidities become less severe to the point where we cannot reject the null of FIRE one to two years after the start of the recession. The degree of information rigidity stays low about two years and then it starts to recover to the level observed before the start of a recession.

These dynamics of information rigidity pose a challenge for popular models of informational frictions such as the sticky information and imperfect information models. In both types of models the choice of frequency of updates or allocation of attention is made given the "average" behavior of the

with Dovern et al. (2010), who rely on dispersion of forecasts and find, that central bank independence plays a more important role in anchoring expectations than inflation targeting among a similar set of countries. 
economy rather than a specific contingency. Agents in these models do not reoptimize every period how much attention should be allocated to tracking macroeconomic conditions and the degree of information rigidity does not vary over the business cycle. Accounting for the business-cycle variation in information rigidity observed in Figure 6 will require models with state-dependent acquisition of information, such as Gorodnichenko (2008), to qualitatively generate variation of informational rigidities over the business cycle and, more generally, in response to aggregate shocks. ${ }^{31}$

\subsubsection{The 9/11 Attacks}

Both models of informational rigidities considered in section 2 imply that the current mean forecast is a weighted average of the previous mean forecast and the current full-information rational expectation forecast, where the weights used in computing the average current forecast in the classical formulations of these models are fixed and thus the diffusion of information is largely time-dependent. For example, under the sticky-information model of Reis (2006), if firms face a fixed cost to acquiring new information, then information updates will be infrequent and time-dependent if no new information can be acquired without paying the fixed cost. But if a large shock occurs which is visible to economic agents, this would induce a state-dependent response and synchronized updating of information as in a state-dependent imperfect information model of Gorodnichenko (2008). As a result, the degree of information rigidity should be much lower after a large and visible shock than during normal periods.

The time period of our analysis includes one such unambiguously visible and economically potent shock: the attacks of September $11^{\text {th }}, 2001$. As shown in Figure 7, the 9/11 attacks were followed by very large downward revisions to U.S. macroeconomic forecasts. For example, in the survey done in August 2001, the consensus forecast for the growth rate of the year-on-year real GDP for 2002Q1 was approximately $2 \%$. In the special October forecasts of professional forecasters organized by Consensus Economics in response to the September $11^{\text {th }}$ attacks, the consensus forecast for the same time period was revised down to $-0.5 \%$. Forecasts of industrial production were similarly substantially lowered as a result of the attacks. However, by February 2002, forecasters had raised their projected growth rates of real GDP back up substantially whereas forecasts of industrial projection growth remained very similar to the initial post-9/11 forecasts. The latter points to a rapid adjustment of expectations in line with the FIRE assumption, whereas the former actually points to overshooting expectations.

\footnotetext{
${ }^{31}$ The substantial decrease in information rigidity during recessions could also be consistent with models in which agents have ambiguity aversion, as in Epstein and Schneider (2008) and Ilut (2010). In these models, rational agents face uncertainty about the true data generating process and place more weight on the less favorable data generating processes. As a result, these models point to information rigidity being insensitive to good news and decreasing strongly in response to bad news, such as recessions.
} 
To quantitatively assess whether the degree of information rigidity varied during the periods immediately following the $9 / 11$ attacks, we create a dummy variable $\left(I_{t}^{9 / 11}\right)$ equal to one in the fourth quarter of 2001 and the first two quarters of 2002. We then consider the following specification

$$
x_{j, t+h}-F_{t} x_{j, t+h}=c+\beta \Delta F_{t} x_{j, t+h}+\gamma\left(\Delta F_{t} x_{j, t+h} \times I_{j t}^{9 / 11}\right)+\alpha I_{j t}^{9 / 11}+\text { error }_{j, h, t} .
$$

The coefficient $\gamma$ on the interaction term of forecast revisions and the $9 / 11$ dummy indicates the difference in the degree of information rigidity associated with the forecast revisions during these three quarters. Results from applying this method to U.S. professional forecasters for those macroeconomic variables available since 1968 as well as the estimates using the larger set of variables from 1982 are presented in Table 8 (columns (1)-(4)) as well as results from applying this test to the cross-country data-set, pooled across all countries, variables, and forecasting horizons (columns (5) and (6)). In each case, the coefficient $\gamma$ is negative and statistically significant, indicating that the degree of information rigidity was lower during the forecast revisions following the 9/11 attacks, as expected in the face of a large and visible shock. In fact, point estimates of $\gamma$ are, if anything, larger in absolute value than the point estimates of $\beta$, so that the forecast revisions can be characterized as either FIRE or even overshooting expectations in the case of the U.S. ${ }^{32}$ Thus, consistent with the predictions of state-dependent models of informational rigidities, large and highly visible economic shocks will lead to much more rapid adjustment of expectations than during run-of-the-mill periods. The fact that our empirical approach can identify and differentiate between these types of forecast revisions lends further credence to the notion that informational frictions are the source of the underlying rigidity in the expectations formation process.

\section{Conclusion}

Building from the predictions of models of informational rigidities, we provide a new test of the null of full-information rational expectations which is informative about the economic significance of departures from the null as well as the models that can account for these departures. The core of the proposed approach is a tight theoretical link between ex post mean forecast errors and ex ante mean forecast revisions. Applying this approach to professional forecasters in the U.S. and other industrialized countries, we document widespread rejections of full-information rational expectations in exactly the direction predicted by models of informational rigidities. Consistent with these models, when one takes into account forecast revisions, other macroeconomic variables lose much of their ability to predict forecast errors. One interpretation of our results is that commonly observed rejections of the null of fullinformation rational expectations most likely reflect deviations from full-information rather than departures from rational expectations. The estimates also point to economically significant estimates of informational rigidities, thereby providing support for the recent body of work studying the integration of

\footnotetext{
${ }^{32}$ Similar results obtain if we focus on U.S. forecasts in the Consensus Economics data.
} 
informational frictions into macroeconomic models. In addition, our approach can shed light on how best to model the expectations formation process: we document a variety of evidence indicating that professional forecasters can adequately be modeled via imperfect information models.

While we have focused primarily on professional forecasters, this approach can be applied to other economic agents. For example, we document qualitatively similar results using the inflation forecasts from the Michigan Survey of Consumers as well as with the inflation forecasts extracted from financial market prices. The former could be extended to study the properties of consumer forecasts of other macroeconomic variables to assess which model best characterizes the expectations formation process of consumers. With financial markets, one could also go beyond implied inflation expectations to assess the importance of informational rigidities using exchange rate and commodity futures prices. Beyond these types of agents, our approach is also well-suited to study informational rigidities on the part of central banks. The Greenbook forecasts of the Federal Reserve, for example, include multiple forecasting horizons for a wide range of macroeconomic variables. Assessing the nature and degree of informational frictions faced by the U.S. central bank could help interpret the historical experience and have implications for optimal policy. In short, our approach can shed new light on the nature of the expectations formation process for different economic agents, as well as quantify the importance of these informational rigidities.

In addition, one can apply our approach to study the implications of different policies on the expectations formation process. For example, we document that the Great Moderation, frequently attributed to the monetary policy changes enacted by Volcker, was associated with a pronounced and persistent increase in the degree of information rigidity for professional forecasters. This finding suggests a new mechanism through which, along with increased risk-taking behavior on the part of financial market participants, the Great Moderation may have played a role in generating the Great Recession. Similarly, our empirical specification can help quantify the effect of policy changes on the expectations formation process, thereby providing a more theoretically grounded notion of otherwise vague concepts such as "anchored" expectations. For example, we provide evidence that central bank independence has had a discernible impact on the expectations formation process among industrialized countries, whereas the adoption of inflation-targeting regimes has had little to no effect on the estimated degree of information rigidity among professional forecasters, thereby casting doubt on the quantitative importance of this policy for expectations. Importantly, this approach can be applied to study a wide variety of other policies such as exchange rate regimes or extended to developing countries and thereby shed new light on one of the key mechanisms via which these policies are supposed to affect dynamics, namely through the expectations formation process. 


\section{References}

Adam, Klaus and Mario Padula, 2003. "Inflation Dynamics and Subjective Expectations in the United States," European Central Bank Working Paper 222.

Andolfatto, David, Scott Hendry, and Kevin Moran, 2007. "Are Inflation Expectations Rational?" Journal of Monetary Economics 55(2), 406-422.

Andrade, Philippe, and Herve Le Bihan, 2010. "Inattentive Professional Forecasters," mimeo.

Ang, Andrew, Geert Bekaert, and Min Wei, 2007. "Do macro variables, asset markets or surveys forecast inflation better?" Journal of Monetary Economics 54(4), 1163-1212.

Arnone, Marco, Bernard J. Laurens, Jean-François Segalotto, and Martin Sommer, 2009. "Central Bank Autonomy: Lessons from Global Trends," IMF Staff Papers 56(June), 263-296.

Bacchetta, Philippe, Elmar Mertens, and Eric van Wincoop. 2008. "Predictability in Financial Markets: What Do Survey Expectations Tell Us?" Forthcoming in Journal of International Money and Finance.

Ball, Laurence, N. Gregory Mankiw and Ricardo Reis, 2005. "Monetary Policy for Inattentive Economies," Journal of Monetary Economics 52 (4), 703-725.

Barro, Robert J., and David B. Gordon, 1983. "Rules, discretion and reputation in a model of monetary policy," Journal of Monetary Economics 12(1), 101-121.

Bauer, Andy, Robert A. Eisenbeis, Daniel F. Waggoner, and Tao Zha, 2003. "Forecast Evaluation with Cross-Section Data: The Blue Chip Surveys," Federal Reserve Bank of Atlanta Economic Review Second Quarter 2003, 17-31.

Bernanke, Ben S. and Frederic S. Mishkin, 1997. "Inflation Targeting: A New Framework For Monetary Policy?" Journal of Economic Perspectives 11(2), 97-116.

Branch, William A., 2007. "Sticky information and model uncertainty in survey data on inflation expectations," Journal of Economic Dynamics and Control 31, 245-276.

Bryan, Michael F. and Linsey Molloy, 2007. "Mirror, Mirror, Who's the Best Forecaster of Them All?" Federal Reserve Bank of Cleveland Economic Commentary 3-15-2007.

Capistran, Carlos, and Manuel Ramos-Francia, 2010. "Does Inflation Targeting Affect the Dispersion of Inflation Expectations," Journal of Money, Credit and Banking, 42(1), 113-134.

Carroll, Christopher D. 2003. "Macroeconomic Expectations of Households and Professional Forecasters," Quarterly Journal of Economics 118(1), 269-298.

Clarida, Richard, Jordi Galí, and Mark Gertler, 2000. "Monetary Policy Rules and Macroeconomic Stability: Evidence and Some Theory," Quarterly Journal of Economics 115(1), 147-180.

Coibion, Olivier and Yuriy Gorodnichenko, 2008. "What can survey forecasts tell us about informational rigidities?" NBER Working Paper 14586.

Coibion, Olivier and Yuriy Gorodnichenko, 2009. "Monetary Policy, Trend Inflation, and the Great Moderation: An Alternative Interpretation," forthcoming in American Economic Review.

Coibion, Olivier, 2010. "Testing the Sticky-Information Phillips Curve," Review of Economics and Statistics 92(1), 87-101.

Comin, D. and S. Mulani, 2004. "Diverging Trends in Aggregate and Firm-level Volatility." Review of Economics and Statistics 88(2), 374-383.

Comin, D. and T. Philippon, 2005. "The Rise in Firm-Level Volatility: Causes and Consequences," NBER Macroeconomics Annual, 167-228

Davis, S., J. Haltiwanger, R. Jarmin, J. Miranda, 2006. "Volatility and Dispersion in Business Growth Rates: Publicly Traded versus Privately Held Firms," NBER WP \#12354.

Davis, Steven J., and James A. Kahn, 2008. "Interpreting the Great Moderation: Changes in the Volatility of Economic Activity at the Macro and Micro Levels," Journal of Economic Perspectives 22(4), $155-180$.

Dovern, Jonas, Ulrich Fritsche, and Jiri Slacalek, 2010. "Disagreement among Forecasters in G-7 Countries," mimeo. 
Driscoll, John C. and Aart C. Kraay, 1998. "Consistent Covariance Matrix Estimation With Spatially Dependent Panel Data," The Review of Economics and Statistics 80(4) 549-560.

Epstein, Larry G. and Martin Schneider, 2008. "Ambiguity, Information Quality and Asset Pricing," Journal of Finance 63(1), 197-228.

Gorodnichenko, Yuriy, 2008. "Endogenous Information, Menu Costs, and Inflation Persistence," NBER WP \#14184.

Gourinchas, Pierre-Olivier and Aaron Tornell, 2004. "Exchange-Rate Puzzles and Distorted Beliefs" Journal of International Economics 64, 303-333.

Gürkaynak, Refet S., Andrew T. Levin and Eric T. Swanson, 2006. "Does Inflation Targeting Anchor Long-Run Inflation Expectations? Evidence from Long-Term Bond Yields in the U.S., U.K., and Sweden," forthcoming in Journal of the European Economic Association.

Haubrich, Joseph, George Pennacchi, and Peter Ritchken, 2008. "Estimating Real and Nominal Term Structures using Treasury Yields, Inflation, Inflation Forecasts and Inflation Swap Rates," Federal Reserve Bank of Cleveland Working Paper 08-10.

Ilut, Cosmin, 2010. "Ambiguity Aversion: Implications for the Uncovered Interest Rate Parity Puzzle," mimeo.

Khan, Hashmat, and Zhenhua Zhu. (2006) "Estimates of the Sticky-Information Phillips Curve for the United States," Journal of Money, Credit and Banking 38(1), 195-207.

Kiley, Michael T., 2007. "A Quantitative Comparison of Sticky Price and Sticky Information Models of Price Setting." Journal of Money, Credit, and Banking, 39(1), 101-125.

Kydland, Finn E. and Edward C. Prescott, 1982. "Time to Build and Aggregate Fluctuations," Econometrica 50(6), 1345-1370.

Laster, David, Paul Bennett, In Sum Geoum, 1999. "Rational Bias in Macroeconomic Forecasts," Quarterly Journal of Economics 114(1) 293-318.

Levin, Andrew T., Fabio M. Natalucci, and Jeremy M. Piger, 2004. "The Macroeconomic Effects of Inflation Targeting," Federal Reserve Bank of St. Louis Review 86(4), 51-80.

Little, Jane Sneddon and Teresa Foy Morano, 2008. "Inflation Targeting - Central Bank Practice Overseas," Federal Reserve Bank of Boston Working Paper 08-1.

Lucas, Robert E., 1972. "Expectations and the Neutrality of Money," Journal of Economic Theory 4(2), 103-124.

Mackowiak, Bartosz and Mirko Wiederholt, 2009. "Optimal Sticky Prices under Rational Inattention," American Economic Review 99(3), 769-803.

Mankiw, N. Gregory and Ricardo Reis, 2002. "Sticky Information Versus Sticky Prices: A Proposal to Replace the New Keynesian Phillips Curve," Quarterly Journal of Economics 117(4), 1295-1328.

Mankiw, N. Gregory, Ricardo Reis, and Justin Wolfers, 2004. "Disagreement about Inflation Expectations," NBER Macroeconomics Annual 2003, 209-248.

McConnell, Margaret, and Gabriel Perez-Quirós. 2000. "Output Fluctuations in the United States: What Has Changed since the Early 1980s?” American Economic Review 90(5), 1464-76.

Mehra, Yash P., 2002. "Survey Measures of Expected Inflation: Revisiting the Issues of Predictive Content and Rationality," Federal Reserve Bank of Richmond Economic Quarterly 88(3), 17-36.

Paciello, Luigi and Mirko Wiederholt, 2010. "Imperfect Information and Optimal Monetary Policy," mimeo.

Patton, Andrew J. and Allan Timmermann, 2010. "Why do forecasters disagree? Lessons from the term structure of cross-sectional dispersion," forthcoming in Journal of Monetary Economics.

Pesaran, M. Hashem and Martin Weale. 2006. "Survey Expectations," in Handbook of Economic Forecasting, G. Elliott, C.W.J. Granger, and A. Timmermann (eds.), North-Holland Press.

Piazzesi, Monika and Martin Schneider, 2008. "Bond Positions, Expectations, and the Yield Curve," Working Paper 2008-02, Federal Reserve Bank of Atlanta.

Reis, Ricardo, 2006. "Inattentive Producers," Review of Economic Studies 73(3), 793-821.

Reis, Ricardo, 2009. "Optimal Monetary Policy Rules in an Estimated Sticky-Information Model," American Economic Journal: Macroeconomics 1(2), 1-28. 
Roberts, John M., 1997. “Is Inflation Sticky?” Journal of Monetary Economics 39(1), 173-196.

Roberts, John M., 1998. "Inflation Expectations and the Transmission of Monetary Policy," Finance and Economics Discussion Series 1998-43, Board of Governors of the Federal Reserve System.

Roger, Scott, 2010. "Inflation Targeting Turns 20," Finance and Development 47(1) 46-49.

Sims, Christopher A., 2003. "Implications of Rational Inattention," Journal of Monetary Economics 50(3), 665-690.

Thomas, Lloyd B., 1999. "Survey Measures of Expected U.S. Inflation," Journal of Economic Perspectives 13(4) 125-144.

Woodford, Michael, 2001. "Imperfect Common Knowledge and the Effects of Monetary Policy," published in P. Aghion, R. Frydman, J. Stiglitz, and M. Woodford, eds., Knowledge, Information, and Expectations in Modern Macroeconomics: In Honor of Edmund S. Phelps, Princeton Univ. Press, 2002. 
Table 1. Tests of the Inflation Expectations Process

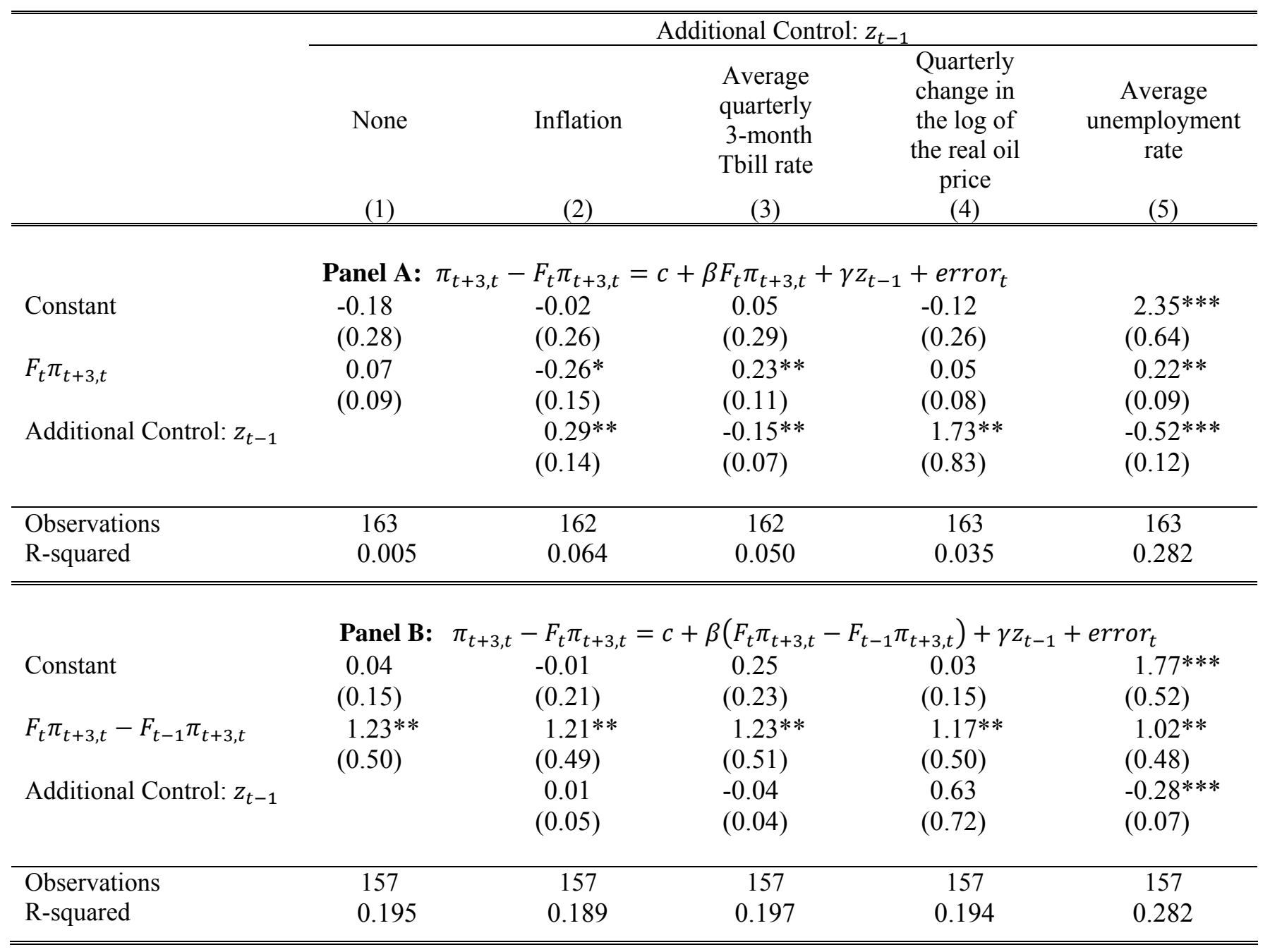

Notes: The table reports coefficient estimates for the specified equations at the top of each panel. The additional controls $(z)$ are lagged by one quarter. Newey-West standard errors are in parentheses. ***, $* *, *$ denote significance at $0.01,0.05$, and 0.10 levels. 
Table 2. Information rigidity in inflation forecasts by forecaster types.

\begin{tabular}{lcccc}
\hline \hline & \multicolumn{4}{c}{ Livingston survey } \\
\cline { 2 - 5 } & & & Non- & \\
& Academic & Commercial & financial & All \\
& Institutions & Banks & Businesses & Forecasters \\
& $(1)$ & $(2)$ & $(3)$ & $(4)$ \\
\hline Forecast revision & $0.448^{*}$ & $0.820^{* * *}$ & $0.616^{* *}$ & $1.023^{* * *}$ \\
& $(0.245)$ & $(0.202)$ & $(0.228)$ & $(0.250)$ \\
Sample & $1969-2010$ & $1969-2010$ & $1969-2010$ & $1969-2010$ \\
Observations & 83 & 83 & 83 & 83 \\
\hline \hline
\end{tabular}

Note: The table reports estimates of equation (10) using inflation forecasts from the Livingston Survey of Professional Forecasters. Columns (1)-(3) report estimates using subsets of the forecasters while column (4) reports estimates using all forecasters in the survey. All estimates are done by OLS with Newey-West HAC standard errors in parentheses. $* * *, * *, *$ denote significance at $0.01,0.05$, and 0.10 levels. 
Table 3. Properties of inflation forecasts

\begin{tabular}{|c|c|c|c|}
\hline & \multicolumn{3}{|c|}{ Panel A: Comparison of Mean Squared Error (MSE) } \\
\hline & $\begin{array}{c}\text { Survey of } \\
\text { Professional } \\
\text { forecasters } \\
\text { (SPF) } \\
\text { (1) }\end{array}$ & $\begin{array}{l}\text { Michigan } \\
\text { Survey of } \\
\text { Consumers } \\
\text { (MSC) } \\
\text { (2) }\end{array}$ & $\begin{array}{c}\text { Financial } \\
\text { markets } \\
(\text { FIN) } \\
(3)\end{array}$ \\
\hline$\overline{\mathrm{MSE}}$ & $\begin{array}{c}1.190 \\
(0.212)\end{array}$ & $\begin{array}{c}2.437 \\
(0.561)\end{array}$ & $\begin{array}{c}1.429 \\
(0.211)\end{array}$ \\
\hline p-value of equality & - & 0.039 & 0.426 \\
\hline \multirow[t]{2}{*}{ Observations } & 112 & 112 & 112 \\
\hline & $\begin{array}{c}\text { Panel B: Pre } \\
\text { (1) }\end{array}$ & $\begin{array}{c}\text { ty of ex post } \\
\text { (2) }\end{array}$ & $\begin{array}{c}\text { lation } \pi_{t, t+4} \\
\text { (3) }\end{array}$ \\
\hline $\mathrm{SPF}, F_{t} \pi_{t, t+4}$ & $\begin{array}{l}0.750 * * \\
(0.364)\end{array}$ & $\begin{array}{l}0.957 * * * \\
(0.281)\end{array}$ & $\begin{array}{l}0.777^{*} \\
(0.409)\end{array}$ \\
\hline $\mathrm{MSC}, F_{t} \pi_{t, t+4}$ & $\begin{array}{l}0.139 \\
(0.310)\end{array}$ & & $\begin{array}{l}0.148 \\
(0.319)\end{array}$ \\
\hline $\mathrm{FIN}, F_{t} \pi_{t, t+4}$ & & $\begin{array}{l}-0.040 \\
(0.270)\end{array}$ & $\begin{array}{l}-0.037 \\
(0.283)\end{array}$ \\
\hline R-squared & 0.297 & 0.277 & 0.285 \\
\hline Observations & 111 & 111 & 111 \\
\hline
\end{tabular}

Notes: In Panel A, figures in parentheses are the standard errors of the MSE estimates. The last row in Panel A reports the p-value of the t-test of equality of MSE for SPF and an alternative source of forecasts. In Panel B, standard errors are in parentheses. $* * *, * *, *$ denote significance at $0.01,0.05$, and 0.10 levels. 
Table 4. Information rigidity in inflation forecasts across surveys.

\begin{tabular}{lccc}
\hline \hline & \multicolumn{3}{c}{ Instrumental variable regression } \\
\cline { 2 - 4 } & $\begin{array}{c}\text { Survey of } \\
\text { Professional } \\
\text { forecasters } \\
(\mathrm{SPF})\end{array}$ & $\begin{array}{c}\text { Michigan } \\
\text { Survey of } \\
\text { Consumers } \\
(1)\end{array}$ & $\begin{array}{c}\text { Financial } \\
\text { markets } \\
(\mathrm{FIN})\end{array}$ \\
\cline { 2 - 4 } Forecast revision & $1.255^{* *}$ & $(2)$ & $(3)$ \\
\hline s.e.e. & $(0.486)$ & $0.738^{* * *}$ & $2.013^{*}$ \\
Observations & 1.155 & 1.258 & $(1.069)$ \\
\hline First stage & 111 & 111 & 1.651 \\
$\quad$ & & & 111 \\
\hline Oil price shock & 1.964 & 2.674 & \\
\hline $\mathrm{R}^{2}$ & $(0.496)$ & $(0.458)$ & 1.340 \\
F-stat & 0.283 & 0.383 & $0.575)$ \\
\hline \hline
\end{tabular}

Notes: The table reports estimated specifications (10) with inflation forecasts. The dependent variable is the ex post mean forecast error. Newey-West robust standard errors are in parentheses. $* * *, * *, *$ denote significance at $0.01,0.05$, and 0.10 levels. Panel B reports the first stage fit. The instrumental variable is oil price shocks which are residuals from projecting changes in the oil prices on its own two lags. 
Table 5. Pooled Estimates of the Expectations Formation Process

\begin{tabular}{|c|c|c|c|c|c|c|c|c|c|}
\hline \multirow{2}{*}{$\begin{array}{c}\text { Dependent variable } \\
\text { Forecast error } \\
x_{t+h}-F_{t} x_{t+h}\end{array}$} & \multicolumn{3}{|c|}{$\begin{array}{l}\text { U.S. SPF } \\
1968-2010 \\
5 \text { Variables }\end{array}$} & \multicolumn{3}{|c|}{$\begin{array}{c}\text { U.S. SPF } \\
1982-2010 \\
13 \text { Variables }\end{array}$} & \multicolumn{3}{|c|}{$\begin{array}{c}\text { Cross-Country Professional } \\
\text { Forecasters } \\
1989-2010 \\
5 \text { Variables } \\
12 \text { countries } \\
\end{array}$} \\
\hline & $\begin{array}{l}\text { OLS } \\
(1) \\
\end{array}$ & $\begin{array}{l}\mathrm{FE} \\
(2) \\
\end{array}$ & $\begin{array}{c}\text { FE } \\
+ \text { time } \\
\text { dummies } \\
(3) \\
\end{array}$ & $\begin{array}{l}\text { OLS } \\
(4) \\
\end{array}$ & $\begin{array}{l}\mathrm{FE} \\
(5) \\
\end{array}$ & $\begin{array}{c}\mathrm{FE} \\
+ \text { time } \\
\text { dummies } \\
(6) \\
\end{array}$ & $\begin{array}{l}\text { OLS } \\
(7) \\
\end{array}$ & $\begin{array}{l}\text { FE } \\
(8) \\
\end{array}$ & $\begin{array}{c}\mathrm{FE} \\
+ \text { time } \\
\text { dummies } \\
(9) \\
\end{array}$ \\
\hline $\begin{array}{l}\text { Forecast revision } \\
\Delta F_{t} x_{t+h}\end{array}$ & $\begin{array}{l}0.387 * * \\
(0.178)\end{array}$ & $\begin{array}{l}0.382 * * \\
(0.177)\end{array}$ & $\begin{array}{l}0.307 * * * \\
(0.118)\end{array}$ & $\begin{array}{l}\text { Panel A } \\
0.653 * * * \\
(0.188)\end{array}$ & $\begin{array}{l}0.653 * * * \\
(0.188)\end{array}$ & $\begin{array}{l}0.634 * * * \\
(0.134)\end{array}$ & $\begin{array}{l}0.690^{* * *} \\
(0.143)\end{array}$ & $\begin{array}{l}0.635 * * * \\
(0.139)\end{array}$ & $\begin{array}{l}0.512 * * * \\
(0.072)\end{array}$ \\
\hline $\begin{array}{l}\text { Observations } \\
\text { R-squared }\end{array}$ & $\begin{array}{l}3,240 \\
0.019 \\
\end{array}$ & $\begin{array}{l}3,240 \\
0.018 \\
\end{array}$ & $\begin{array}{l}3,240 \\
0.129 \\
\end{array}$ & $\begin{array}{l}5,793 \\
0.030 \\
\end{array}$ & $\begin{array}{l}5,793 \\
0.032 \\
\end{array}$ & $\begin{array}{l}5,793 \\
0.080 \\
\end{array}$ & $\begin{array}{c}22,341 \\
0.047 \\
\end{array}$ & $\begin{array}{c}22,341 \\
0.043 \\
\end{array}$ & $\begin{array}{c}22,341 \\
0.234 \\
\end{array}$ \\
\hline $\begin{array}{l}F_{t} x_{t+h} \\
F_{t-1} x_{t+h}\end{array}$ & $\begin{array}{l}0.421^{* *} \\
(0.173) \\
-0.481 * * \\
(0.171)\end{array}$ & $\begin{array}{l}0.429 * * \\
(0.174) \\
-0.530 * * * \\
(0.184)\end{array}$ & $\begin{array}{c}0.359 * * \\
(0.111) \\
-0.483 * * * \\
(0.074)\end{array}$ & $\begin{array}{l}\text { Panel B } \\
0.651 * * * \\
(0.179) \\
-0.576^{* * *} \\
(0.181)\end{array}$ & $\begin{array}{l}0.670 * * * \\
(0.179) \\
-0.506 * * \\
(0.202)\end{array}$ & $\begin{array}{l}0.631 * * * \\
(0.154) \\
-0.491 * * \\
(0.180)\end{array}$ & $\begin{array}{l}0.721 * * * \\
(0.140) \\
-0.782 * * * \\
(0.119)\end{array}$ & $\begin{array}{l}0.663 * * * \\
(0.131) \\
-0.736 * * * \\
(0.096)\end{array}$ & $\begin{array}{l}0.525 * * * \\
(0.106) \\
-0.541 * * * \\
(0.082)\end{array}$ \\
\hline $\begin{array}{l}\mathrm{p} \text {-value }(\beta+\gamma)=0 \\
\text { Observations } \\
\text { R-squared }\end{array}$ & $\begin{array}{l}0.135 \\
3,240 \\
0.022\end{array}$ & $\begin{array}{l}0.234 \\
3,240 \\
0.023\end{array}$ & $\begin{array}{l}0.257 \\
3,240 \\
0.135\end{array}$ & $\begin{array}{l}0.258 \\
5,793 \\
0.032 \\
\end{array}$ & $\begin{array}{l}0.104 \\
5,793 \\
0.039 \\
\end{array}$ & $\begin{array}{l}0.207 \\
5,793 \\
0.086 \\
\end{array}$ & $\begin{array}{l}0.073 \\
22,341 \\
0.0731\end{array}$ & $\begin{array}{l}0.233 \\
22,341 \\
0.046\end{array}$ & $\begin{array}{l}0.625 \\
22,341 \\
0.234\end{array}$ \\
\hline
\end{tabular}

Notes: The table reports estimated specifications (10) and (12) in Panels A and B respectively. Driscoll-Kraay (1998) standard errors are in parentheses in columns (1), (2), (4), (5), (7), (8). Robust standard errors clustered by forecasted variable are in parentheses in columns (3), (6) and (9). Fixed effects in columns (2), (3), (5), (6), (8) and (9) are for each combination of country, variable, and forecast horizon. Time dummies in columns (3), (6) and (9) are for each time period (calendar quarter). $* * *, * *, *$ denote significance at $0.01,0.05$, and 0.10 levels. 
Table 6. The Macroeconomic Determinants of Informational Rigidities

\begin{tabular}{|c|c|c|c|c|c|}
\hline \multirow{2}{*}{$\begin{array}{l}\text { Dependent variable: } \\
\text { estimated coefficient on } \\
\text { forecast revisions for } \\
\text { country-variable pairs }\end{array}$} & \multicolumn{3}{|c|}{$\begin{array}{c}\text { Revisions in data releases as } \\
\text { a measure of noise }\end{array}$} & \multicolumn{2}{|c|}{$\begin{array}{c}\text { Forecast disagreement as } \\
\text { a measure of noise }\end{array}$} \\
\hline & $\begin{array}{l}\text { OLS } \\
(1) \\
\end{array}$ & $\begin{array}{c}\text { OLS } \\
\text { exclude } \\
\text { outliers } \\
(2) \\
\end{array}$ & $\begin{array}{c}\text { Robust } \\
\text { regression } \\
(3) \\
\end{array}$ & $\begin{array}{l}\text { OLS } \\
(4) \\
\end{array}$ & $\begin{array}{c}\text { Robust } \\
\text { regression } \\
\quad(5) \\
\end{array}$ \\
\hline Persistence of Series, $\rho_{i, j}$ & $\begin{array}{l}-0.802 * * * \\
(0.282)\end{array}$ & $\begin{array}{l}-0.833 * * * \\
(0.248)\end{array}$ & $\begin{array}{l}-0.628^{*} \\
(0.317)\end{array}$ & $\begin{array}{l}-1.068 * * * \\
(0.269)\end{array}$ & $\begin{array}{l}-1.146^{* * *} \\
(0.354)\end{array}$ \\
\hline Noise-Signal Ratio, $\kappa_{i, j}$ & $\begin{array}{c}0.153 \\
(0.304)\end{array}$ & $\begin{array}{l}0.464 * * \\
(0.201)\end{array}$ & $\begin{array}{r}0.506^{*} \\
(0.255)\end{array}$ & $\begin{array}{l}0.871 * * \\
(0.425)\end{array}$ & $\begin{array}{r}0.790^{*} \\
(0.476)\end{array}$ \\
\hline $\begin{array}{l}\text { Observations } \\
\text { R-squared }\end{array}$ & $\begin{array}{c}60 \\
0.153 \\
\end{array}$ & $\begin{array}{c}56 \\
0.326 \\
\end{array}$ & 60 & $\begin{array}{c}48 \\
0.196 \\
\end{array}$ & 48 \\
\hline
\end{tabular}

Note: The table reports estimated specification (16). The persistence of each series $\left(\rho_{i, j}\right)$ is estimated as the sum of AR(4) coefficients. In columns (1)-(3), standard deviation of the difference between first and final data releases is taken as a measure of noise in the series. In columns (4) and (5), the average standard deviation of forecast disagreement is taken as a measure of noise in the series. In column (1), four observations are identified as outliers: consumption growth rates for Italy, France, Germany and Japan. These outliers are dropped in estimation in column (2). In columns (3) and (5), robust S-regression is run with no dummies for outliers and all available observations included. Robust standard errors are in parentheses. $* * * * *, *$ denote significance at $0.01,0.05$, and 0.10 levels. 
Table 7. Informational rigidities and inflation targeting.

\begin{tabular}{|c|c|c|c|c|c|c|}
\hline \multirow[t]{2}{*}{$\begin{array}{c}\text { Dependent variable } \\
\text { Forecast error } \\
\pi_{j, t+h}-F_{t} \pi_{j, t+h}\end{array}$} & \multicolumn{2}{|c|}{$\begin{array}{c}\text { Canada, 1991-present } \\
\text { UK, 1992-present } \\
\text { Sweden, 1993-present } \\
\text { Norway, 2001-present } \\
\text { Spain, 1995-1998 }\end{array}$} & \multicolumn{2}{|c|}{$\begin{array}{c}\text { Canada, 1991-present } \\
\text { UK, 1992-present } \\
\text { Sweden, 1993-present } \\
\text { Norway, 2001-present } \\
\text { Spain, 1995-1998 } \\
\text { Euro area, 1999-present }\end{array}$} & \multicolumn{2}{|c|}{$\begin{array}{c}\text { Canada, 1991-present } \\
\text { UK, 1992-present } \\
\text { Sweden, 1993-present } \\
\text { Norway, 2001-present } \\
\text { Spain, 1995-1998 } \\
\text { Euro area, 1999-present } \\
\text { USA, 1989-present } \\
\text { Germany, 1989-present } \\
\text { Switzerland, 1989-present }\end{array}$} \\
\hline & $\begin{array}{c}\text { OLS } \\
(1) \\
\end{array}$ & $\begin{array}{l}\mathrm{FE} \\
(2) \\
\end{array}$ & $\begin{array}{c}\text { OLS } \\
(3) \\
\end{array}$ & $\begin{array}{l}\mathrm{FE} \\
(4) \\
\end{array}$ & $\begin{array}{c}\text { OLS } \\
(5) \\
\end{array}$ & $\begin{array}{l}\mathrm{FE} \\
(6) \\
\end{array}$ \\
\hline$\overline{\Delta F_{t} \pi_{j, t+h}}$ & $\begin{array}{l}0.200^{*} \\
(0.111)\end{array}$ & $\begin{array}{l}0.168 \\
(0.105)\end{array}$ & $\begin{array}{c}0.121 \\
(0.109)\end{array}$ & $\begin{array}{c}0.088 \\
(0.107)\end{array}$ & $\begin{array}{c}0.139 \\
(0.130)\end{array}$ & $\begin{array}{c}0.119 \\
(0.135)\end{array}$ \\
\hline$\Delta F_{t} \pi_{j, t+h} \times I T_{j t}$ & $\begin{array}{c}0.062 \\
(0.140)\end{array}$ & $\begin{array}{c}0.057 \\
(0.144)\end{array}$ & $\begin{array}{r}0.177^{*} \\
(0.105)\end{array}$ & $\begin{array}{c}0.137 \\
(0.095)\end{array}$ & $\begin{array}{c}0.114 \\
(0.153) \\
\end{array}$ & $\begin{array}{c}0.078 \\
(0.151)\end{array}$ \\
\hline $\begin{array}{l}\text { Observations } \\
\text { R-squared }\end{array}$ & $\begin{array}{l}4,541 \\
0.019 \\
\end{array}$ & $\begin{array}{l}4,541 \\
0.015 \\
\end{array}$ & $\begin{array}{l}4,541 \\
0.018 \\
\end{array}$ & $\begin{array}{l}4,541 \\
0.030 \\
\end{array}$ & $\begin{array}{l}4,541 \\
0.019 \\
\end{array}$ & $\begin{array}{l}4,541 \\
0.029 \\
\end{array}$ \\
\hline
\end{tabular}

Notes: The table reports estimated specification (17). $I T_{t}$ is the dummy variable equal to one if a country targets inflation in a given time period and zero otherwise. In columns (1) and (2) the set of inflation targeting countries includes only countries with an explicit mandate to target inflation. In columns (3) and (4), the set of inflation countries is augmented with countries in the Euro area since the European Central Bank admits an inflation target. In columns (5) and (6), the set of inflation countries is further augmented with the USA, Germany and Switzerland. Driscoll-Kraay (1998) standard errors are in parentheses. ***, $* *$, denote significance at $0.01,0.05$, and 0.10 levels. 
Table 8. 9/11.

\begin{tabular}{|c|c|c|c|c|c|c|}
\hline \multirow[t]{2}{*}{$\begin{array}{c}\text { Dependent variable } \\
\text { Forecast error } \\
x_{t+h}-F_{t} x_{t+h}\end{array}$} & \multicolumn{2}{|c|}{$\begin{array}{c}\text { U.S. SPF } \\
\text { 1968-2010 } \\
5 \text { Variables }\end{array}$} & \multicolumn{2}{|c|}{$\begin{array}{c}\text { U.S. SPF } \\
1982-2010 \\
13 \text { Variables }\end{array}$} & \multicolumn{2}{|c|}{$\begin{array}{c}\text { Cross-Country } \\
\text { Professional } \\
\text { Forecasters } \\
1989-2010 \\
5 \text { Variables } \\
12 \text { countries }\end{array}$} \\
\hline & $\begin{array}{c}\text { OLS } \\
(1)\end{array}$ & $\begin{array}{l}\mathrm{FE} \\
(2) \\
\end{array}$ & $\begin{array}{c}\text { OLS } \\
(3) \\
\end{array}$ & $\begin{array}{l}\text { FE } \\
(4) \\
\end{array}$ & $\begin{array}{c}\text { OLS } \\
(5) \\
\end{array}$ & $\begin{array}{l}\text { FE } \\
(6) \\
\end{array}$ \\
\hline$\Delta F_{t} x_{t+h}$ & $\begin{array}{l}0.414 * * * \\
(0.049)\end{array}$ & $\begin{array}{l}0.407 * * * \\
(0.045)\end{array}$ & $\begin{array}{l}0.713 * * * \\
(0.139)\end{array}$ & $\begin{array}{l}0.732 * * * \\
(0.148)\end{array}$ & $\begin{array}{l}0.736^{* * *} \\
(0.060)\end{array}$ & $\begin{array}{l}0.681 * * * \\
(0.058)\end{array}$ \\
\hline$\Delta F_{t} x_{t+h} \times I_{t}^{9 / 11}$ & $\begin{array}{l}-0.894 * * \\
(0.222)\end{array}$ & $\begin{array}{l}-0.851^{* *} \\
(0.219)\end{array}$ & $\begin{array}{l}-1.041^{* * * *} \\
(0.274)\end{array}$ & $\begin{array}{l}-1.011^{* * *} \\
(0.267)\end{array}$ & $\begin{array}{l}-0.826^{* * * *} \\
(0.129)\end{array}$ & $\begin{array}{l}-0.828^{* * * *} \\
(0.117)\end{array}$ \\
\hline $\mathrm{p}$-value $(\beta+\gamma)=0$ & $<0.01$ & $<0.01$ & $<0.01$ & $<0.01$ & 0.467 & 0.209 \\
\hline Observations & 3,240 & 3,240 & 5,793 & 5,793 & 22,341 & 22,341 \\
\hline R-squared & 0.022 & 0.021 & 0.035 & 0.036 & 0.051 & 0.047 \\
\hline
\end{tabular}

Notes: The table reports estimated specification (19). $I_{t}^{9 / 11}$ is a dummy variable equal to one in 2001Q4, 2002Q1, and 2002Q2 and zero otherwise. $p$-value $(\beta+\gamma)=0$ shows the probability value for the null that the coefficients on $\Delta F_{t} \pi_{t+h}$ and $\Delta F_{t} x_{t+h} \times I_{t}^{9 / 11}$ sum up to zero. Driscoll-Kraay (1998) standard errors are in parentheses. $* * *, * *, *$ denote significance at $0.01,0.05$, and 0.10 levels. 
Figure 1: Inflation Forecasts from Professional Forecasters, Consumers and Financial Markets

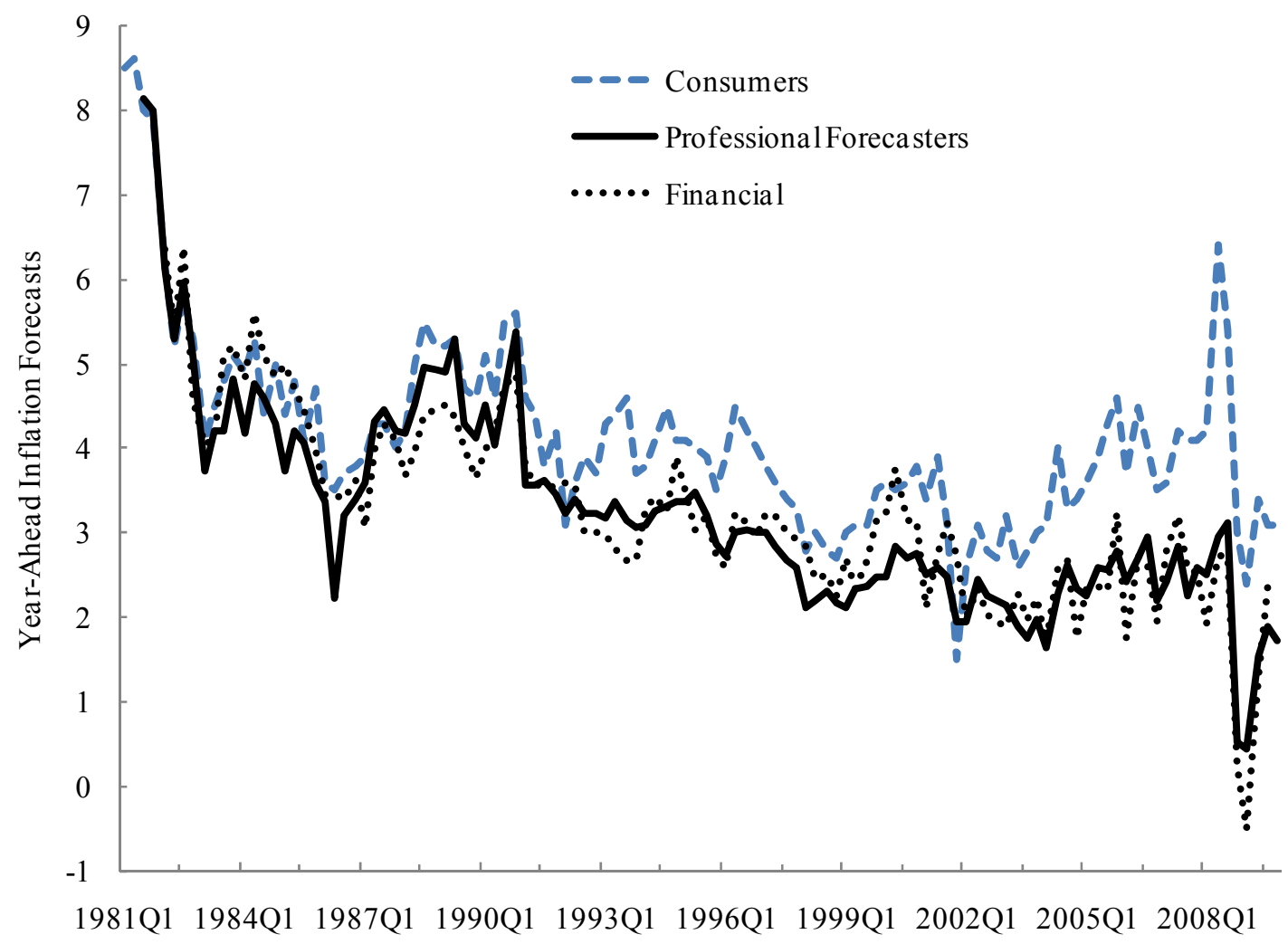

Note: The figure plots the one-year ahead CPI forecasts from the Survey of Professional Forecasters, the Michigan Survey of Consumers, and financial markets. See section 3.3 for details. 
Figure 2: Country-Specific Estimates of Informational Rigidities

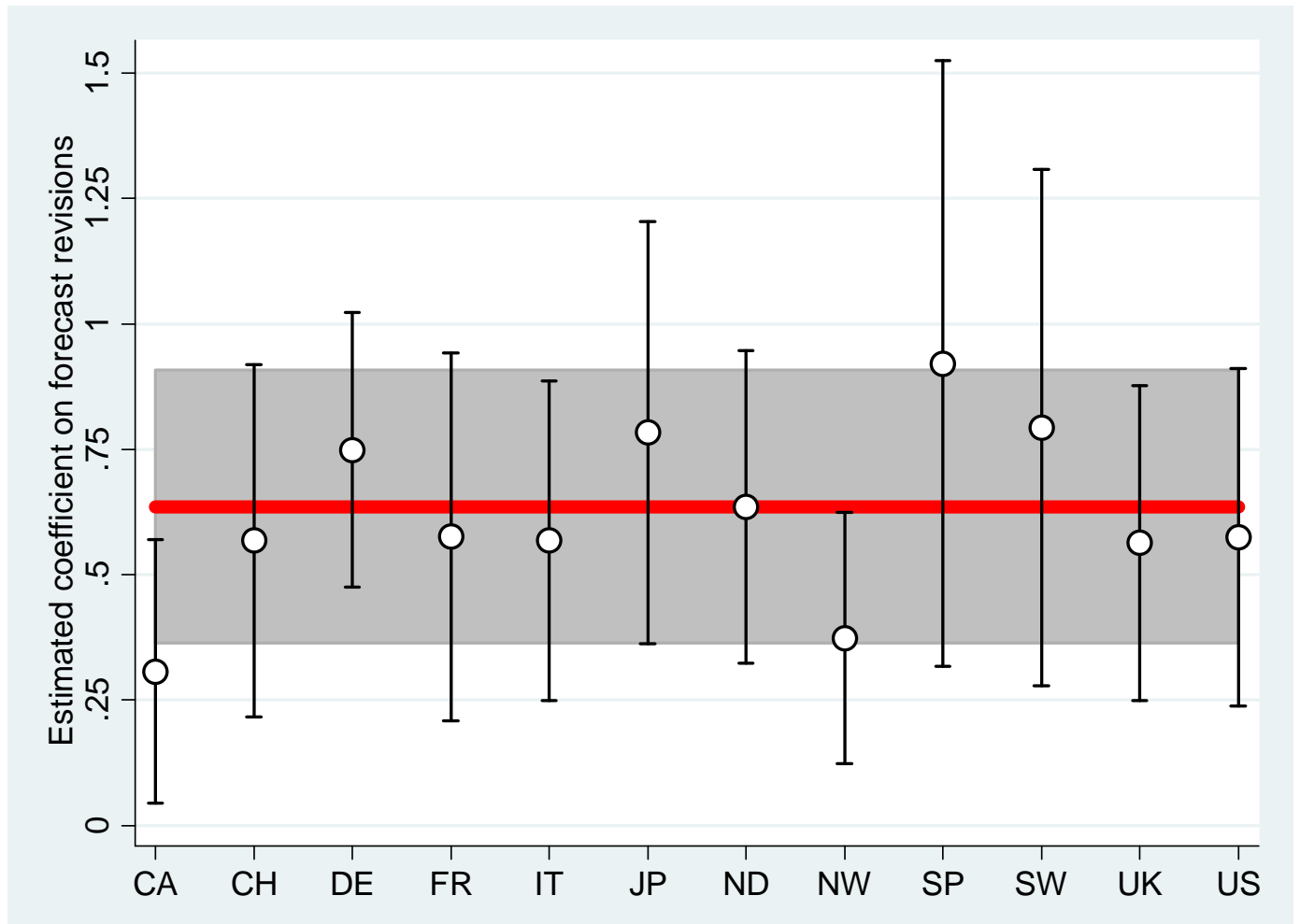

Notes: The figure plots estimated coefficient $\beta$ on forecast revisions in specification (10) for each country separately. Each circle presents a point estimate for a given country and whiskers show the $95 \%$ confidence interval. The solid red line is the point estimate of the coefficient on forecast revisions in specification (10) on pooled (across countries) sample with the shaded region showing the associated 95\% confidence interval. All standard errors are Driscoll and Kraay (1998). CA = Canada, CH = Switzerland, $\mathrm{DE}=$ Germany, FR $=$ France, $\mathrm{IT}=$ Italy, JP $=$ Japan, ND = Netherlands, NW = Norway, $\mathrm{SP}=\mathrm{Spain}, \mathrm{SW}$ $=$ Sweden, UK $=$ United Kingdom, US = USA. 
Figure 3: Estimates of Information Rigidity by Macroeconomic Variable

Panel A: U.S. SPF Variables Available 1968-2010
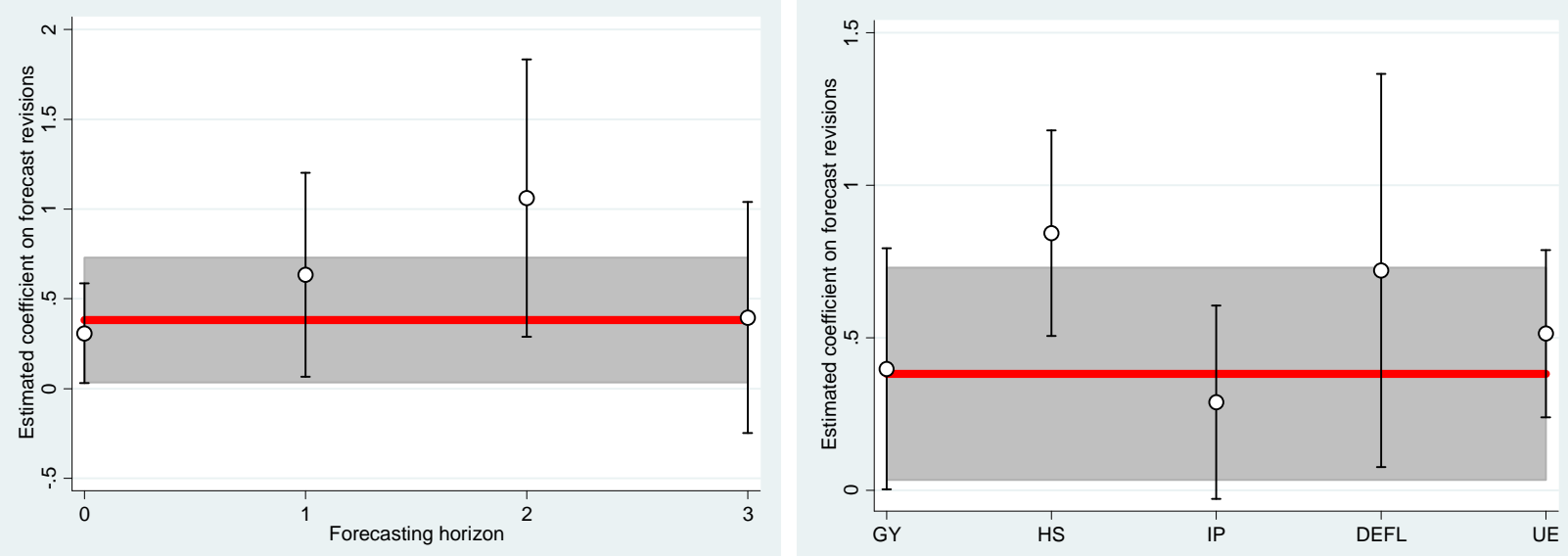

Panel B: U.S. SPF Variables Available 1982-2010
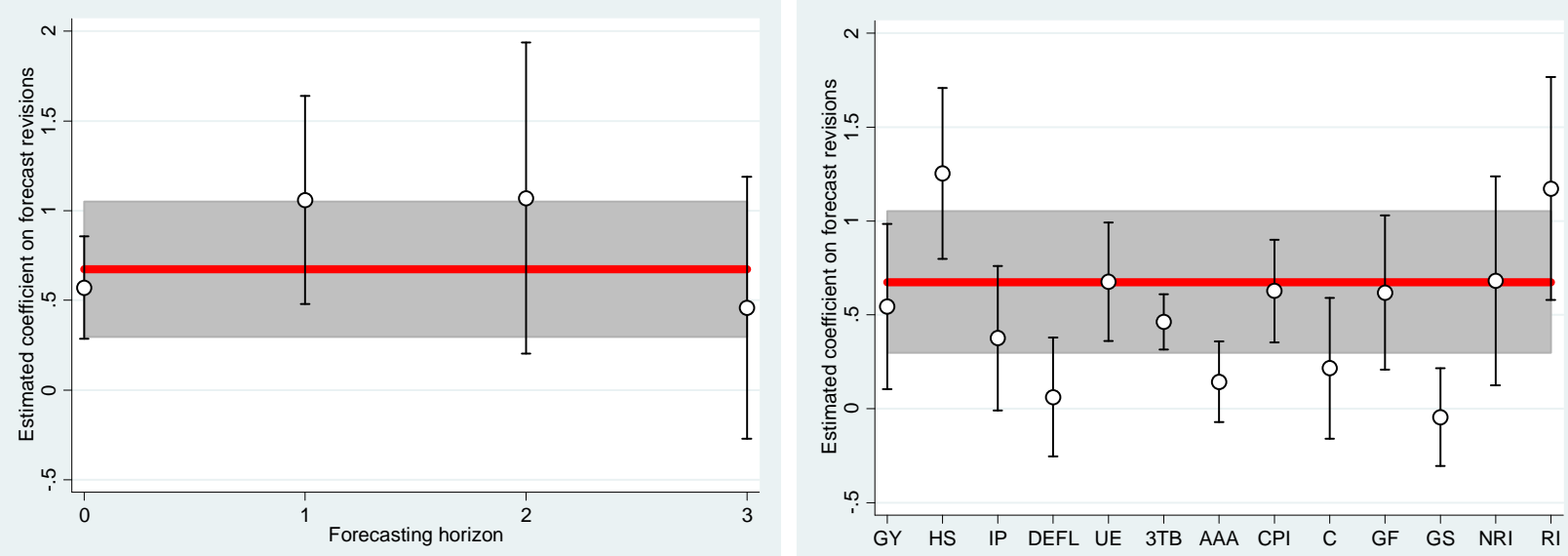

Panel C: Variables Available in Cross-Country Panel Data
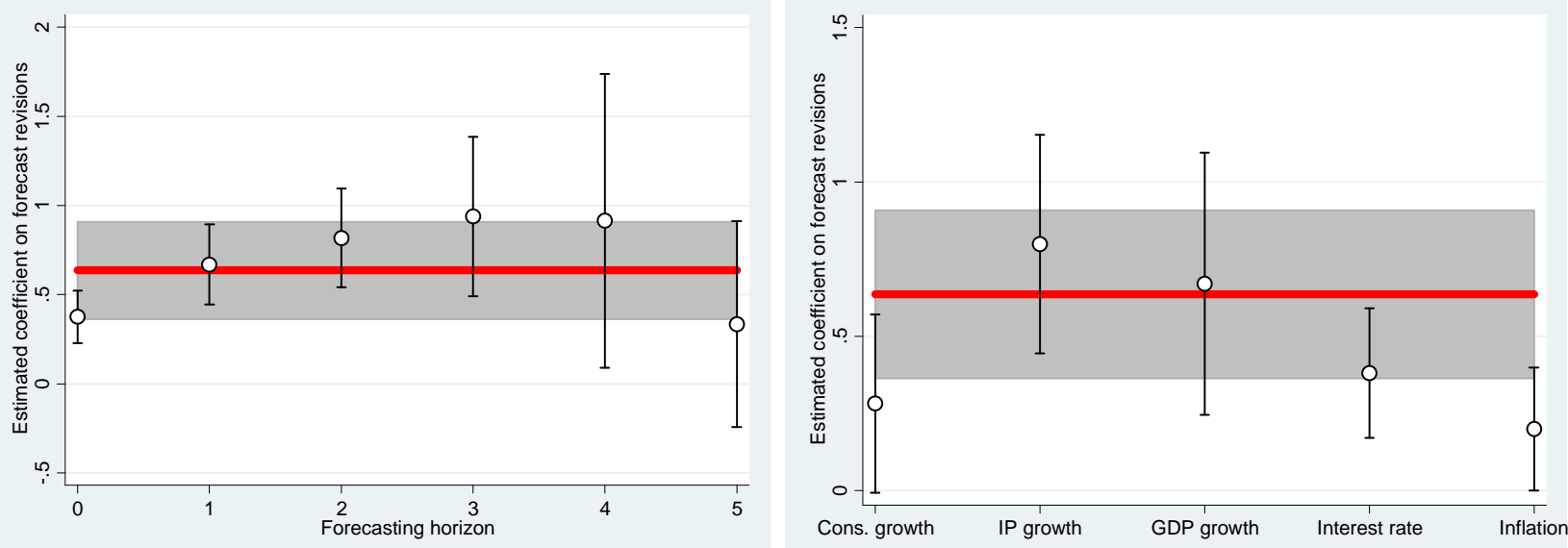

Notes: The figure plots estimated coefficient $\beta$ on forecast revisions (left column) and macroeconomic variables (right column) in specification (10) for each variable separately. Each circle presents a point estimate for a given country and whiskers show the $95 \%$ confidence interval. The solid red line is the point estimate of the coefficient on forecast revisions in specification (10) on pooled (across variables) sample with the shaded region showing the associated $95 \%$ confidence interval. All standard errors are Driscoll and Kraay (1998). GY = real GDP growth rate, HS = Housing starts, IP = Growth rate of industrial production index, DEFL = Inflation rate for GDP deflator, $\mathrm{UE}=$ Unemployment rate, $3 \mathrm{~TB}=3$ month treasure bill interest rate, $\mathrm{AAA}=$ Interest rate on AAA debt, $\mathrm{CPI}=$ Inflation rate for the consumer price index, $\mathrm{C}=$ Consumption growth rate, $\mathrm{GF}=$ growth rate of federal government consumption expenditures, $\mathrm{GS}=\mathrm{Growth}$ rate of state government consumption expenditures, $\mathrm{NRI}=$ Growth rate of non-residential investment; $\mathrm{RI}=$ growth rate of residential investment. 
Figure 4: Information Rigidity and the Great Moderation

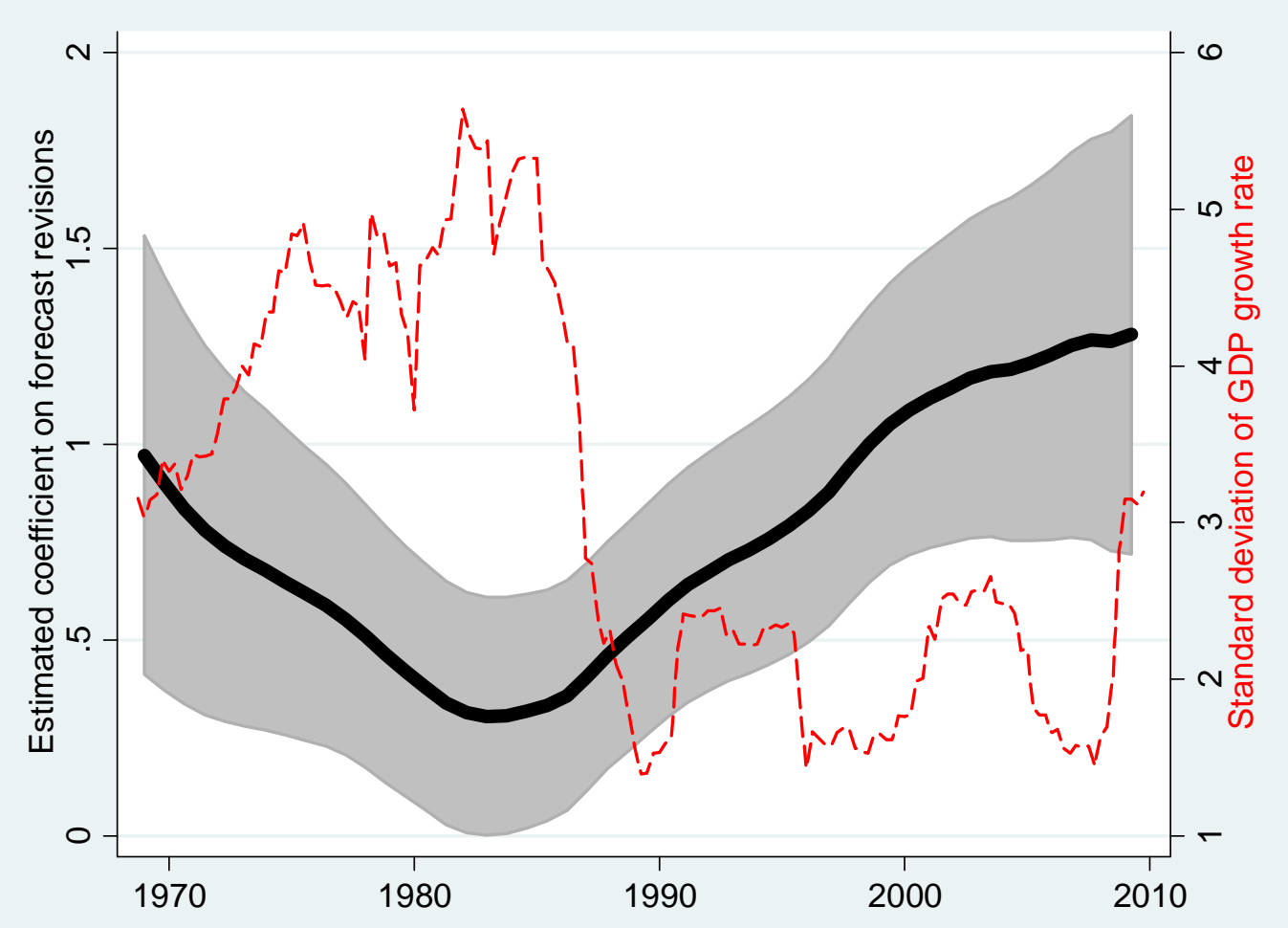

Notes: the figure plots the time series of two variables. The first is the standard deviation of the U.S. real GDP growth rate (annualized) over a five year moving window (red dash line; right axis). The second is the smoothed coefficient $\beta_{t}$ on forecast revisions in specification (10) estimated for each quarter separately on the SPF data (black thick solid line; left axis). The shaded region is the $95 \%$ confidence interval. The smoother is a local average which uses Epanechnikov kernel with bandwidth equal to five. 
Figure 5: Central Bank Independence and Information Rigidity

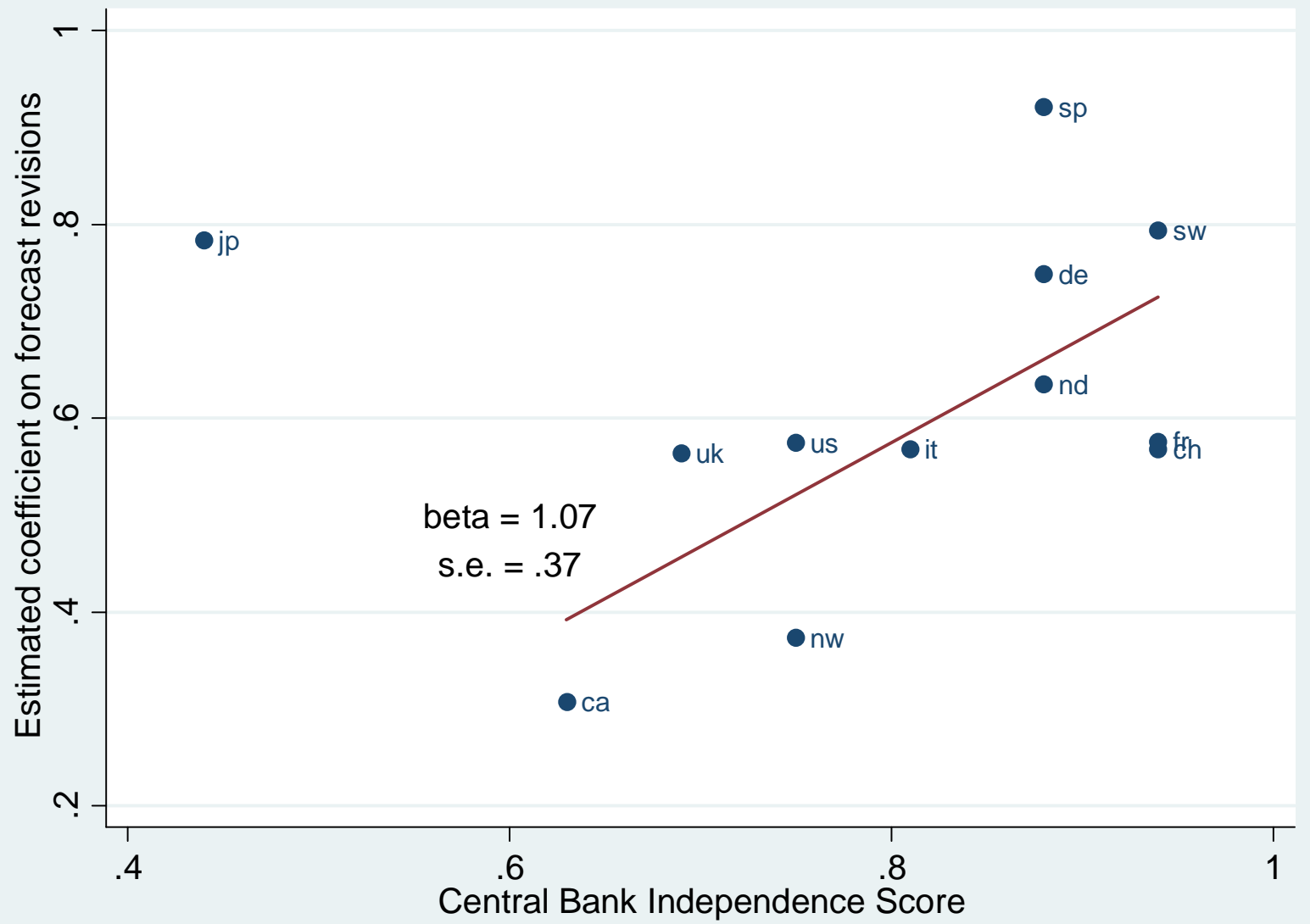

Notes: The figure plots estimated coefficient $\beta$ on forecast revisions in specification (10) for each country separately against the Central Bank Independence Score constructed in Arnone et al. (2007). Each circle represents a country. The solid red line is the fitted line from the Huber robust regression. $\mathrm{CA}=\mathrm{Canada}$, $\mathrm{CH}=$ Switzerland, $\mathrm{DE}=$ Germany, FR $=$ France, $\mathrm{IT}=$ Italy, JP = Japan, ND = Netherlands, NW = Norway, $\mathrm{SP}=$ Spain, $\mathrm{SW}=$ Sweden, UK $=$ United Kingdom, US = USA. 
Figure 6: Information Rigidity during a Business Cycle

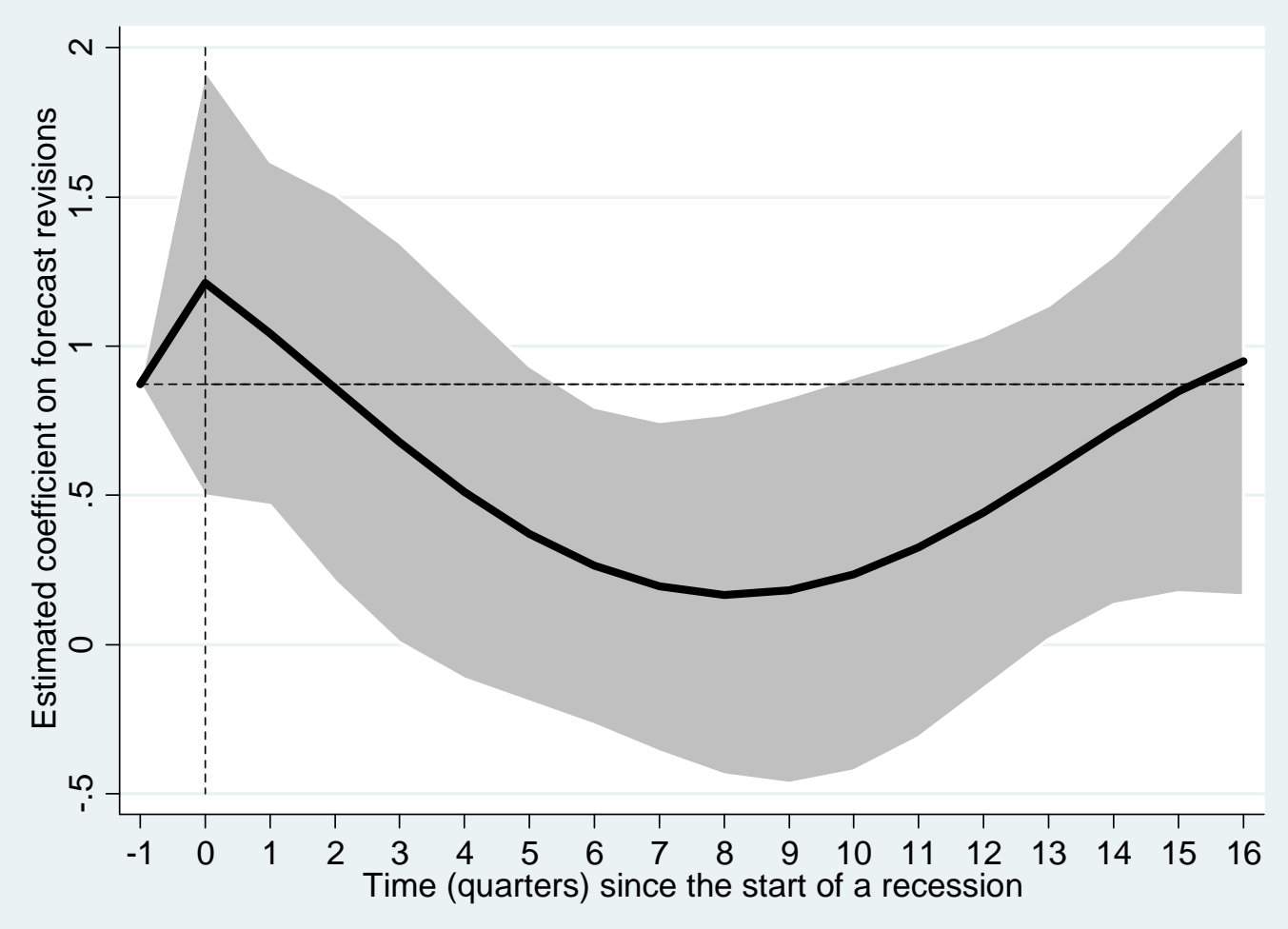

Notes: the figure plots the response of the coefficient $\beta_{t}$ on forecast revisions in specification (10) estimated for each quarter separately on the SPF data. The response is estimated as in specification (18). The response is normalized to be at the average value of the coefficient $\beta_{t}$ one period before a recession starts. The shaded region is the $95 \%$ confidence interval. The horizontal, thin, dashed line shows the average value of the coefficient $\beta_{t}$. The vertical, thin, dashed line shows the time when economy moves into a recession. 
Figure 7: Forecasts of U.S. Production Before and After the September $1^{\text {th }}$, 2001 Attacks: Panel A: Real GDP Growth Rate

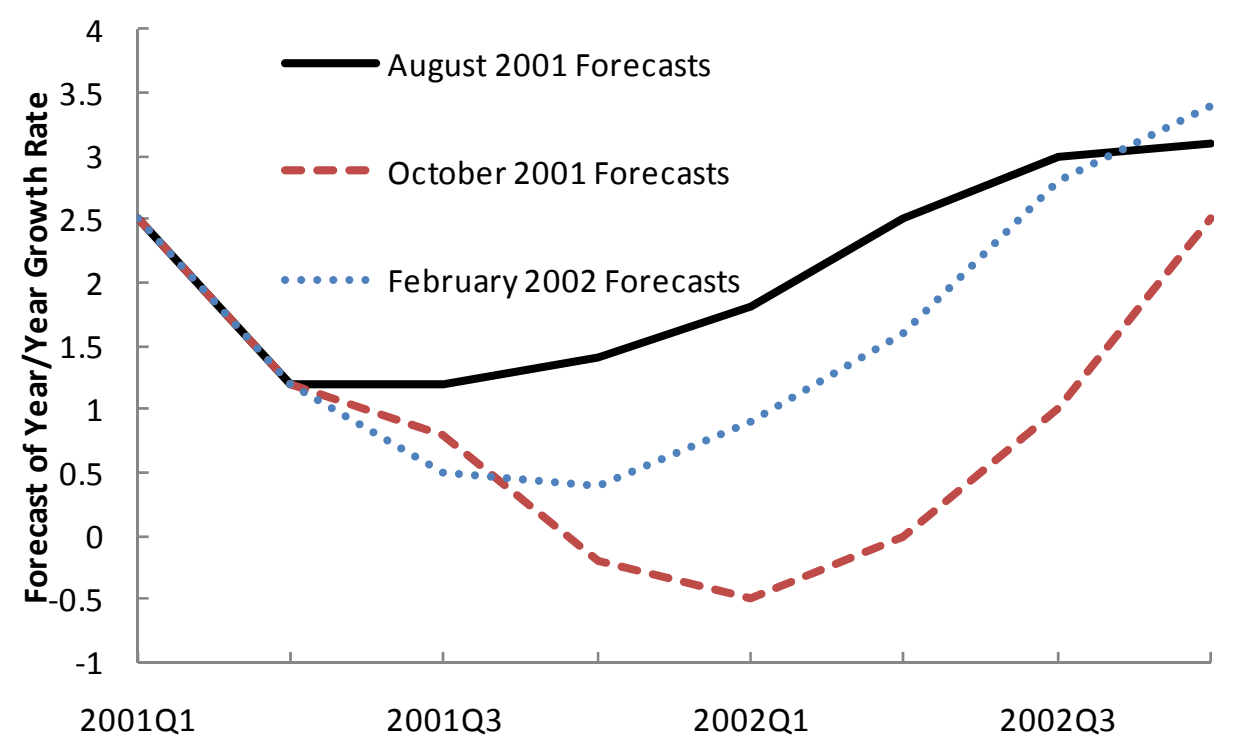

Panel B: Industrial Production Growth Rate

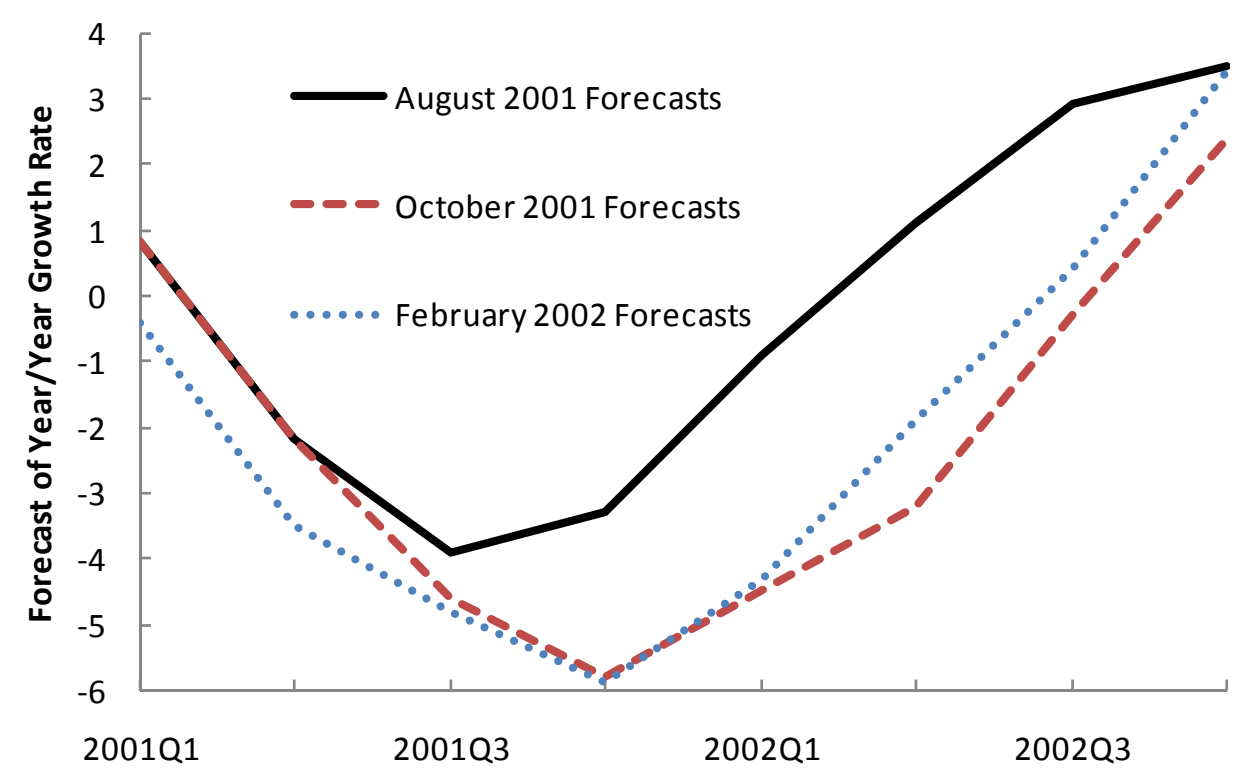

Note: The figure plots consensus forecasts of real GDP growth rates (top panel) and industrial production growth rates (bottom panel) from thee different surveys of professional forecasters by Consensus Economics. 


\section{Appendix Figure 1: Noise-Signal Ratios and Estimated Coefficients on Forecast Revisions}

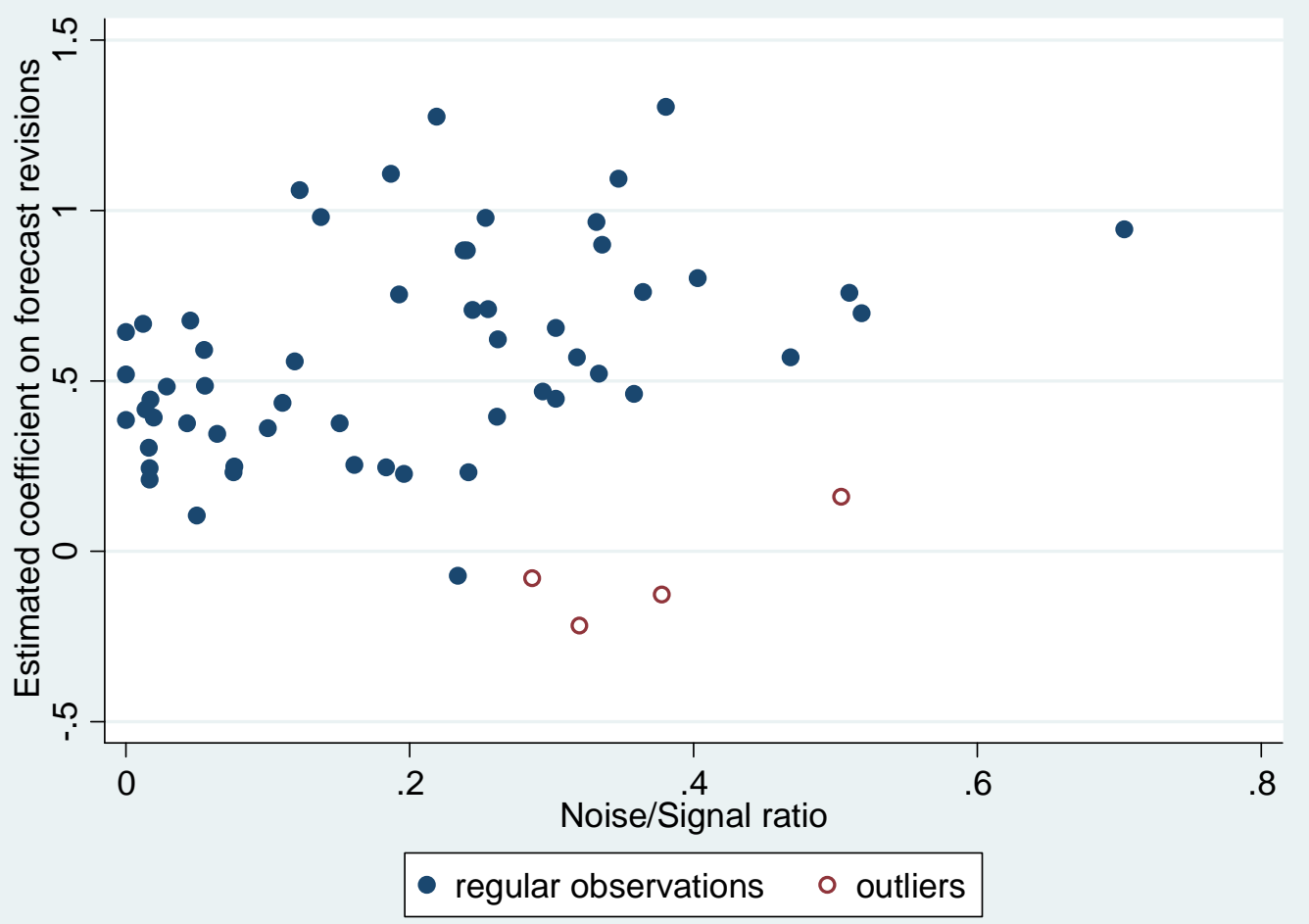

Note: The table plots the noise/signal ratio for each country/variable pair (horizontal axis) where noise is measured using the size of revisions to the data, as discussed in section 4.1. The vertical axis indicates the coefficient on forecast revisions from estimating (15) for each country/macroeconomic variable pair. The empty circles are outliers as identified by robust S-regression of (16) in the text. 